\title{
Fiscal Policy Stabilization: Purchases or Transfers? *
}

\author{
Neil R. Mehrotra ${ }^{\dagger}$
}

This Draft: August 15, 2014

\begin{abstract}
Both government purchases and transfers figure prominently in the use of fiscal policy for counteracting recessions. However, existing representative agent models including the neoclassical and New Keynesian benchmark rule out transfers by assumption. This paper provides a role for transfers by building a borrower-lender model with equilibrium credit spreads and monopolistic competition. The model demonstrates that a broad class of deficit-financed government expenditures can be expressed in terms of purchases and transfers. With flexible prices and in the absence of wealth effects on labor supply, transfers and purchases have no effect on aggregate output and employment. Under sticky prices and no wealth effects, fiscal policy is redundant to monetary policy. Alternatively, in the presence of wealth effects, multipliers for both purchases and transfers will depend on the behavior of credit spreads, but purchases are preferred to transfers under reasonable calibrations due to its larger wealth effect on labor supply. When the zero lower bound is binding, both purchases and transfers are effective in counteracting a recession, but the size of the transfer multiplier relative to the purchases multiplier is increasing in the debt elasticity of the credit spread.
\end{abstract}

Keywords: fiscal policy, transfers, zero lower bound.

JEL Classification: E62

*I would like to thank Gauti Eggertsson, Ricardo Reis, and Michael Woodford for helpful discussions, and Guido Lorenzoni, Bruce Preston, Guilherme Martins, Stephanie Schmitt-Grohe, Dmitriy Sergeyev, and seminar participants at the Federal Reserve Board and Boston University for useful comments. First draft: April 1, 2011.

${ }^{\dagger}$ Brown University, Department of Economics, e-mail: neil_mehrotra@brown.edu 


\section{Introduction}

The Great Recession has brought renewed attention to the possibility of using fiscal policy to counteract recessions. Policymakers in developed nations have adopted a series of historically large fiscal interventions in an attempt to raise output, reduce unemployment, and stabilize consumption and investment. In the US, in addition to increases in government purchases, policymakers have also relied heavily on transfers of various forms - to individuals, institutions, and state and local governments - as instruments of fiscal policy. Table 1 provides the Congressional Budget Office breakdown of the various components of the Recovery Act and estimates for the associated policy multiplier. Transfers account for more than half of the expenditures in the Recovery Act.

Table 1: Outlays and Estimated Policy Multipliers for American Recovery and Reinvestment Act

\begin{tabular}{lccc} 
Category & Estimated Multiplier (High) & Estimated Multiplier (Low) & Outlays \\
\hline \hline Purchases of goods and services by the federal government & 2.5 & 1.0 & $\$ 88 \mathrm{bn}$ \\
Transfers to state and local governments for infrastructure & 2.5 & 1.0 & $\$ 44 \mathrm{bn}$ \\
Transfers to state and local governments not for infrastructure & 1.9 & 0.7 & $\$ 215 \mathrm{bn}$ \\
Transfers to persons & 2.2 & 0.8 & $\$ 100 \mathrm{bn}$ \\
One-time Social Security payments & 1.2 & 0.2 & $\$ 18 \mathrm{bn}$ \\
Two-year tax cuts for lower and middle income persons & 1.7 & 0.5 & $\$ 168 \mathrm{bn}$ \\
One-year tax cuts for higher income persons (AMT fix) & 0.5 & 0.1 & $\$ 70 \mathrm{bn}$ \\
\hline
\end{tabular}

Recent work has shown that households display a sizable propensity to consume out of transfers. Empirical work by Johnson, Parker and Souleles (2006) demonstrate that an economically significant portion of tax rebates (intended as stimulus) are spent. The authors track changes in consumption in the Consumer Expenditures Survey and use the timing of rebates as a source of exogenous variation. Similarly, Agarwal, Liu and Souleles (2007) examine the effect of the 2001 tax rebates on consumption and saving using credit card data, finding dynamic effects on both credit card balances and spending over the subsequent year.

While the empirical evidence provides suggestive evidence that transfers may be an effective form of stimulus, macroeconomic models are needed to determine conditions under which transfers can counteract recessions. While an extensive literature has analyzed the determinants of the government purchases multiplier, comparatively little work has focused on determinants of the transfers multiplier. This paper seeks to address that gap.

In this paper, I examine the determinants of the transfers multiplier in a New Keynesian borrower-lender model. The model features patient and impatient households, with the latter serving as the borrowers in this economy. The borrowing rate depends on a credit spread that rises 
with the aggregate level of debt outstanding. I examine fiscal multipliers under both flexible prices and sticky prices to isolate the channels through which fiscal policy affects output and employment.

My analysis reveals that several insights from the representative agent setting carry over to a multiagent setting with credit spreads. Under flexible prices, fiscal policy only affects output and employment through a wealth effect on labor supply. If preferences or the structure of labor markets eliminate wealth effects on labor supply, neither purchases nor transfers will have any effect on output or employment. Even in the presence of wealth effects, the deviations from the representative agent benchmark are small for plausible calibrations. The government purchases multiplier on output is positive but less than one and driven by the negative wealth effect on labor supply, while the transfers multiplier is close to zero as wealth effects lead to offsetting movements in hours worked by the households that provide and receive the transfer.

Under sticky prices, fiscal policy now generally has both a supply effect (via wealth effect on labor supply) and a demand effect (via countercyclical markups). In the special case of no wealth effects, a Phillips curve can be derived in terms of output and inflation. So long as a central bank is free to adjust the nominal rate, the central bank may implement any combination of output and inflation irrespective of the stance of fiscal policy. In this sense, fiscal policy is irrelevant for determining aggregate output or inflation since monetary policy is free to undo any effect of fiscal policy. More generally, the tradeoff between purchases and transfers will depend on the monetary policy rule. In the presence of wealth effects, purchases or transfers may lower wages and shift the Phillips curve. Under a Taylor rule and a standard calibration, transfers continue to have small effects on output and employment relative to purchases. The primacy of monetary policy in determining the effect of fiscal policy is analogous to the conclusions of Woodford (2011) and Curdia and Woodford (2010). The presence of a credit spread and intermediation alters the implementation of monetary policy (rule) but not the feasible set (Phillips curve).

When the central bank is not free to adjust the interest rate when, for example, the zero lower bound on the nominal interest rate is binding, the choice between purchases and transfers becomes relevant and monetary policy cannot substitute for fiscal policy. Moreover, the behavior of the credit spread and its dependence on endogenous variables will determine the merits of purchases versus transfers. In the model, an exogenous shock to the credit spread causes the zero lower bound to bind. Under the calibration considered, purchases act directly to increase output and inflation while transfers work indirectly by allowing for a faster reduction in private sector debt, thereby lowering spreads. Both types of policies allow a faster escape from the zero lower bound relative to 
no intervention due to the endogenous effect of debt reduction on credit spreads, and consumption multipliers for each policy are typically positive. A credit spread that is more sensitive to changes in private sector debt (higher debt elasticity) raises the transfer multiplier.

The debt elasticity of the credit spread plays a key role in determining the transfer multiplier and the choice between transfers and government purchases. An increase in the debt elasticity boosts the transfer multiplier through two channels. A higher debt elasticity raises the marginal propensity to consume out of temporary income for the borrower household increasing the demand effect from transfers. Additionally, with a high debt elasticity, credit spreads fall lowering the cost of borrowing and further increasing borrower income. This credit market effect is unique to this environment and is not present in models with rule of thumb households.

The paper is organized as follows: Section 2 briefly summarizes related literature on fiscal policy in a non-representative agent setting, and its role in stabilizing business cycles. Section 3 presents the model and introduces credit spreads and fiscal policy. Section 4 compares purchases and transfers in the case of no wealth effects on labor supply. Alternatively, Section 5 considers purchases and transfers in the presence of wealth effects. Section 6 examines the effect of purchases and transfers at the zero lower bound and Section 7 concludes. $^{1}$

\section{Related Literature}

This paper contributes to several distinct strands of literature that examine fiscal policy in nonrepresentative agent settings. A literature beginning with Mankiw (2000) examines fiscal policy in models with rule of thumb agents - agents who do not participate in financial markets and simply consume their income each period. Gali, Lopez-Salido and Valles (2007) examine the effect of ruleof-thumb consumers on the government purchases multiplier and find that the presence of these agents can boost the multiplier above one. ${ }^{2}$

The research question explored in this paper is probably closest to Giambattista and Pennings (2012) who also analyze determinants of the transfer multiplier both away and at the zero lower bound in a model with rule of thumb agents. The model considered here is more general by allowing for intertemporal optimization on the part of borrower households, which better accords with the empirical evidence of persistent consumption responses after tax rebates as documented in Agarwal,

\footnotetext{
${ }^{1}$ The Appendix relates the credit spread model considered here to models with rule-of-thumb households, models with borrowing constraints, and overlapping generations models.

${ }^{2}$ Nominal rigidities and labor market frictions in their model have substantial effects on the government purchases multiplier even in the absence of rule-of-thumb consumers.
} 
Liu and Souleles (2007). Moreover, the model considered here nests rule of thumb behavior as a limiting case. As the debt elasticity of the credit spread approach infinity, borrower households fully spend any transfer.

A small literature has studied the conduct of fiscal policy for stabilization purposes in quantitative heterogenous agent models with incomplete markets. Heathcote (2005) considers the short-run effect of tax cuts in a model with idiosyncratic income risk, finding a fairly small tax cut multiplier. Similarly, Oh and Reis (2012) consider the effect of targeted transfers as fiscal stimulus and find very low transfer multipliers. In their model, labor supply responses by donor and receipient households largely offset. In comparison to these models, the model considered here is fairly tractable and allows me to isolate and identify mechanisms at work in more complex settings.

This paper also relates to a literature examining the effect of credit shocks at the zero lower bound like Eggertsson and Krugman (2012) and Guerrieri and Lorenzoni (2011) that show how deleveraging shocks cause a binding zero lower bound. My setting differs from these papers by introducing a more general type of financial friction. Like the rule of thumb case, the fiscal multipliers obtained in Eggertsson and Krugman (2012) are a special case of my model as the debt elasticity approaches infinity. Importantly, since credit spreads are partly determined endogenously, the time to exit the zero lower bound is endogenous to fiscal policy in contrast to Eggertsson and Woodford (2003) and other representative agent treatments of fiscal multipliers at the zero lower bound.

Finally, this paper has implications for recent work by Kaplan and Violante (2011) that considers household consumption and saving decisions in the presence of illiquid assets. Their model replicates the fairly high observed marginal propensity to consume out of tax rebates. In contrast to their work and other microfounded models of the consumption function, this paper considers a simple credit spread as the financial friction. This simplification allows for the analysis of the transfer multiplier in general equilibrium. In comparison, income is exogenous in Kaplan and Violante (2011) and the real interest rate is held constant. As I will argue, the insights about the determinants of the transfer multiplier discussed here carry over in environments with more complex microfoundations.

\section{Model}

The model consists of two types of households, monopolistically competitive firms, a monetary authority that sets the deposit rate as its policy instrument, and a fiscal authority. To generate borrowing and lending in steady state, the lender and borrower household are assumed to differ 
in their rates of time preference. An equilibrium credit spread is introduced to ensure that both agent's Euler equations are satisfied in steady state.

The model of patient and impatient agents used here draws on the borrower-saver model used in Campbell and Hercowitz (2005), Iacoviello (2005), and Monacelli (2009) where different rates of time preference among households allow for borrowing and lending in steady state. Differing rates of time preference are a staple in financial accelerator models such as Bernanke, Gertler and Gilchrist (1999), but these models typically go further and link the discount rate to the structure of production. The structure of the model considered here closely relates to the model used by Bilbiie, Monacelli and Perotti (2012) which focuses on the aggregate effects of income redistribution. The two-agent model facilitates the introduction of sticky prices and monetary policy to examine aggregate demand effects, and allows for the use of log-linearization to understand the key mechanisms at work.

\subsection{Households}

A measure $1-\eta$ of patient household chooses consumption and real savings to maximize discounted expected utility:

$$
\begin{aligned}
& \max _{\left\{C_{t}^{s}, N_{t}^{s}, D_{t}\right\}} \quad E \sum_{t=0}^{\infty} \beta^{t} U\left(C_{t}^{s}, N_{t}^{s}\right) \\
& \text { subject to } C_{t}^{s}=W_{t} N_{t}^{s}+\frac{1+i_{t-1}^{d}}{\Pi_{t}} D_{t-1}-D_{t}+\Pi_{t}^{f}-T_{t}
\end{aligned}
$$

where $D_{t}$ is real savings of the patient household, $\Pi_{t}$ is the gross inflation rate, and $\Pi_{t}^{f}$ are any profits from the real or financial sectors. ${ }^{3}$ The government may collect non-distortionary lump sum taxes $T_{t}$ that are levied uniformly across households. The period utility function $U(C, N)$ is twice continuously differentiable, increasing, and concave in consumption: $U_{c}(C, N)>0, U_{c c}(C, N)<0$ and decreasing and convex in hours: $U_{h}(C, N)<0, U_{h h}(C, N)<0$. While patient households could choose to borrow, for sufficiently small shocks, the interest rate on borrowings would be too high and the patient household only saves.

A measure $\eta$ of impatient household chooses consumption and real borrowings to maximize

\footnotetext{
${ }^{3}$ If equity in the firms and intermediaries were traded and short-selling ruled out, the patient household would accumulate all shares in steady state. For sufficiently small shocks, the assumption that patient households own all shares would continue to hold in the stochastic economy.
} 
discounted expected utility:

$$
\begin{aligned}
& \max _{\left\{C_{t}^{b}, N_{t}^{b}, B_{t}\right\}} \quad E_{0} \sum_{t=0}^{\infty} \beta_{b}^{t} U\left(C_{t}^{b}, N_{t}^{b}\right) \\
& \text { subject to } C_{t}^{b}=W_{t} N_{t}^{b}+B_{t}-\frac{1+i_{t-1}^{b}}{\Pi_{t}} B_{t-1}-T_{t}
\end{aligned}
$$

where $B_{t}$ is the real borrowings of the impatient household. The impatient household's discount rate $\beta_{b}<\beta$ ensures that the household chooses not to save and to only borrow in the neighborhood of the steady state. The impatient household's optimality conditions are analogous to those of the patient household and standard:

$$
\begin{aligned}
\lambda_{t}^{i} & =U_{c}\left(C_{t}^{i}, N_{t}^{i}\right) \\
\lambda_{t}^{i} W_{t} & =-U_{h}\left(C_{t}^{i}, N_{t}^{i}\right) \\
\lambda_{t}^{s} & =\beta E_{t} \lambda_{t+1}^{s} \frac{1+i_{t}^{d}}{\Pi_{t+1}} \\
\lambda_{t}^{b} & =\beta_{b} E_{t} \lambda_{t+1}^{b} \frac{1+i_{t}^{b}}{\Pi_{t+1}}
\end{aligned}
$$

for $i \epsilon\{s, b\}$ in equations (1) and (2). The difference between the borrowing rate and the deposit rate allows both agents Euler equations to be satisfied in the non-stochastic steady state, with the interest rates determined by the patient and impatient household's discount rates.

Aggregate consumption $C_{t}$ and labor supply $N_{t}^{\text {sup }}$ are simply the weighted sum of each household's consumption and labor supply:

$$
\begin{aligned}
C_{t} & =\eta C_{t}^{b}+(1-\eta) C_{t}^{s} \\
N_{t}^{\text {sup }} & =\eta N_{t}^{b}+(1-\eta) N_{t}^{s}
\end{aligned}
$$

As my analysis demonstrates, wealth effects play a critical role in determining the effect of fiscal policy on output, employment and consumption.

Definition 1. Wealth effects are absent from household labor supply if the household's labor supply has the following representation:

$$
W_{t}=v_{i}\left(N_{t}^{i}\right)
$$

for some function $v_{i}$ that is increasing. 
Wealth effects on labor supply are eliminated under the preference specification considered by Greenwood, Hercowitz and Huffman (1988):

$$
U(C, N)=\frac{\left(C-\gamma N^{1+\frac{1}{\varphi}}\right)^{1-\sigma}}{1-\sigma}
$$

where $\varphi$ is the Frisch elasticity of labor supply. Under GHH preferences, labor supply takes the form shown in the definition:

$$
W_{t}=\gamma\left(1+\frac{1}{\varphi}\right)\left(N_{t}^{i}\right)^{1 / \varphi}
$$

Aside from GHH preferences, wealth effects on labor supply would also be absent in a model with labor market rigidities. Under a rigid real wage, the labor supply relation no longer holds for each household:

$$
W_{t}>\frac{-U_{h}\left(C_{t}^{i}, N_{t}^{i}\right)}{U_{c}\left(C_{t}^{i}, N_{t}^{i}\right)}
$$

for $i \epsilon\{s, b\}$. In a model where wages remained constant - the case of perfect wage rigidity considered by (Blanchard and Gali, 2010) and Shimer (2012) - fiscal multipliers are determined exclusively by firm's labor demand condition. Under wage rigidity, household's labor supply can be represented (locally) by a constant function $v_{i}\left(N_{t}^{i}\right)=c=\bar{W}$ satisfying the definition of no wealth effects.

To obtain an aggregate labor supply curve and an aggregate IS curve, I must log-linearize the household's labor supply and Euler equations. In the general case with wealth effects, labor supply is a function of the aggregate wage and the household's consumption:

$$
w_{t}=\frac{1}{\varphi_{i}} n_{t}^{i}+\frac{1}{\sigma_{i}} c_{t}^{i}
$$

for $i \epsilon\{s, b\}$ where the lower case variables represent $\log$ deviations from steady state, $\varphi_{i}$ is the household's Frisch elasticity and $\sigma_{i}$ is the household's intertemporal elasticity of substitution. Solving for each agent's labor supply $n_{t}^{i}$, aggregate labor supply is the weighted sum of each agent's log-linearized labor supply (where the weight is the steady state share of employment for each household). Similarly, an aggregate IS equation can be obtained by a weighted sum of each agent's log-linearized Euler equation:

$$
\begin{aligned}
w_{t} & =\frac{1}{\tilde{\varphi}} n_{t}+l_{b} \frac{\varphi_{b}}{\tilde{\varphi} \sigma_{b}} c_{t}^{b}+\left(1-l_{b}\right) \frac{\varphi_{s}}{\tilde{\varphi} \sigma_{s}} c_{t}^{s} \\
c_{t} & =E_{t} c_{t+1}+s_{b} \sigma_{b} i_{t}^{b}+\left(1-s_{b}\right) \sigma_{s} i_{t}^{d}-\tilde{\sigma} E_{t} \pi_{t+1}
\end{aligned}
$$


with $l_{b}=\eta \bar{N}_{b} / \bar{N}$ and $s_{b}=\eta \bar{C}_{b} / \bar{C}$. The parameters $\tilde{\varphi}=l_{b} \varphi_{b}+\left(1-l_{b}\right) \varphi_{s}$ and $\tilde{\sigma}=s_{b} \sigma_{b}+\left(1-s_{b}\right) \sigma_{s}$ are the appropriate weighted aggregate Frisch elasticity and aggregate intertemporal elasticity of substitution respectively. Relative to a standard representative household model, the labor supply curve depends on the distribution of consumption (as opposed to just the level of consumption) and the IS curve depends on the real borrowing rate (in addition to the real deposit rate).

\subsection{Credit Spreads}

The credit spread - the difference between the borrowing rate and deposit rate - is treated as a reduced form equation:

$$
\frac{1+i_{t}^{b}}{1+i_{t}^{d}}=1+\omega_{t}=E_{t} \Gamma\left(B_{t}, W_{t+1} N_{t+1}^{b}, Z_{t}\right)
$$

The function $\Gamma$ is assumed to be weakly increasing in its first and last arguments and weakly decreasing in its middle argument. The assumption that the spread is increasing with the level of household debt $B_{t}$ is needed to ensure determinacy of the rational expectations equilibrium and is analogous to the stationarity conditions needed in small open economy models. ${ }^{4}$ The effect of expected borrower income, $W_{t+1} N_{t+1}^{b}$ on credit spreads is consistent with the observed countercyclicality of credit spreads and the fact that spreads lead the business cycle.

The shock $Z_{t}$ is an exogenous financial shock that can increase spreads. The financial shock may be interpreted as either a shock to the supply or demand side of the credit market. On the supply side, if financial intermediaries' capacity to raise funds is constrained by their own net worth, a depletion of equity due to an unexpected loss on the asset side of the balance sheet will cause an increase in borrowing rates. Alternatively, on the demand side, a shock to borrower collateral can likewise make borrowers less creditworthy thereby raising spreads. In particular, in a model with housing as collateral, a shock to house prices would reduce the value of collateral and raise credit spreads for the borrower household.

The log-linearized credit spread can be summarized by two parameters: the elasticity of the spread to private borrowings and the elasticity of the spread to borrower income with $\chi_{b}>0$ and $\chi_{n} \geq 0$ :

$$
\omega_{t}=\chi_{b} b_{t}-\chi_{n} E_{t}\left(w_{t+1}+n_{t+1}^{b}\right)+z_{t}
$$

A debt elasticity greater than or equal to zero is needed to ensure determinacy. If $\chi_{b}=0$, then private sector debt follows a random walk. The credit spread may rise due to an exogenous increase

\footnotetext{
${ }^{4}$ See discussion in Schmitt-Grohé and Uribe (2003).
} 
in $z_{t}$ or may rise due to some fundamental shock that drives up the level of debt or decreases borrower's household income. The log-linearized credit spread is flexible enough to incorporate the type of interest rate spreads seen in a broad class of models. When $\chi_{n}=0$, the model exhibits a debt elastic spread as in standard small open economy models. When $\chi_{b}=\chi_{n}>0$, the credit spread varies with the leverage of the borrower household. The canonical financial accelerator model of Bernanke, Gertler and Gilchrist (1999) features a leverage elastic spread. Finally, when $\chi_{n}>\chi_{b}>0$, the credit spread may be described as income elastic strengthening comovement with the business cycle. As noted earlier, we will show that when $\chi_{b}$ becomes very large, borrower households act like rule-of-thumb households exhibiting a marginal propensity to consume of one out of temporary income. In this way, the credit spread model is more general then the cases considered in related work by Giambattista and Pennings (2012) and Eggertsson and Krugman (2012).

The credit spread here is introduced in a reduced form way to facilitate the analysis of the transfer multiplier in a tractable way. A model with household income shocks and default would be a far more appealing microfoundation but would greatly complicate adding factors like pricing frictions and the zero lower bound that are critical for determining the macroeconomic effect of transfers on output.

If the dependence of the credit spread on future borrower income is dropped, then this model of the credit spread has the same microfoundations as Curdia and Woodford (2010). The authors offered two possible interpretations for the credit spread and its dependence on aggregate borrowing. Firstly, the spread function may reflect real costs of intermediation that are increasing in the level of borrowing. ${ }^{5}$ Alternatively, the credit spread could reflect predictable losses from making loans to fradulent borrowers. Credit spreads would rise with aggregate borrowing if monitoring becomes more difficult with more loans outstanding. ${ }^{6}$

\subsection{Fiscal and Monetary Policy}

The instruments of fiscal policy consist of a set of uniform nondistortionary taxes, government consumption, and transfers. The fiscal authority may also run a budget deficit subject to a fiscal rule that ensures that the debt returns to its steady state level and subject to an intertemporal

\footnotetext{
${ }^{5}$ For example, some fraction of patient households would operate the financial intermediaries and collect labor income in return for making loans.

${ }^{6}$ The microfoundations for the dependence of the credit spread on borrower income are harder to justify in this setting. However, the debt elasticity is a far more important parameter than the income elasticity of the credit spread. Assuming $\chi_{n}=0$ does not greatly change results.
} 
solvency condition:

$$
\begin{aligned}
G_{t} & =B_{t}^{g}-\frac{1+i_{t-1}^{d}}{\Pi_{t}} B_{t-1}^{g}+T_{t} \\
T_{t} & =\phi_{b}\left(B_{t-1}^{g}-\bar{B}_{g}\right)-r e b_{t} \\
0 & =\lim _{T \rightarrow \infty} E_{t} \frac{P_{t}}{P_{T}} \frac{B_{T}^{g}}{\prod_{t}^{T}\left(1+i_{t-1}^{d}\right)}
\end{aligned}
$$

where $r e b_{t}$ is a lump sum tax rebate delivered to all households. The instruments of fiscal policy are government purchases $G_{t}$ and a reduction in lump sum taxes $r e b_{t}$. The government's cost of funds is the policy rate $i_{t}^{d}$, not the borrowing rate $i_{t}^{b}$. This assumption best fits larger economies like the United States where the government controls the currency. For small open economies and countries in a currency union (such as the Eurozone), the rate at which the government borrows may carry a premium to the policy rate.

The monetary authority is assumed to set a rule for monetary policy so long as its instrument of policy, the deposit rate $i_{t}^{d}$, is not constrained by the zero lower bound. I will consider when monetary policy follows a standard Taylor rule (without interest rate smoothing) or pursues perfect inflation stabilization away from the zero lower bound:

$$
\begin{aligned}
\left(\frac{i_{t}^{d}}{\bar{r}_{d}}\right) & =\left(\Pi_{t}\right)^{\phi_{\pi}}\left(\frac{Y_{t}}{Y_{t}^{n}}\right)^{\phi_{y}} \\
\Pi_{t} & =1
\end{aligned}
$$

where $\bar{r}_{d}=\frac{\bar{i}_{d}}{\bar{\Pi}}$. When monetary policy is constrained by the zero lower bound, I assume that the deposit rate is set at zero or inflation is perfectly stabilized.

\subsection{Firms}

Monopolistically competitive firms set prices periodically and hire labor in each period to produce a differentiated good. Cost-minimization for firms and production function play a key role in examining the effects of various fiscal policy shocks and are given below:

$$
\begin{aligned}
M C_{t} & =\frac{W_{t} N_{t}}{\alpha Y_{t}} \\
Y_{t} & =N_{t}^{\alpha}
\end{aligned}
$$


where $\alpha$ is the labor share, $N_{t}$ is labor demand and $M C_{t}$ is the firm's marginal cost which varies over time depending on the rate of inflation and the stance of monetary policy.

Prices are reset via Calvo price setting where $\theta$ is the likelihood of firm to reset its prices in the current period. When $\theta=1$, prices are set each period, monopolistic competitive firms set prices as a fixed markup over marginal costs:

$$
\frac{P_{i t}}{P_{t}}=\frac{\nu}{\nu-1} M C_{t}
$$

where $\nu$ is the elasticity of substitution among final goods in the Dixit-Stiglitz aggregator. If the initial price level is unity, then prices will be normalized to unity, and marginal costs will be fixed at all periods $M C_{t}=\overline{M C}=1 / \mu_{p}$ where $\mu_{p}=\frac{\nu}{\nu-1}$. When $\theta<1$, firms will set prices on the basis of future expected marginal costs. The firms prices problem and the behavior of the price level are summarized by the following equations:

$$
\begin{aligned}
F_{t} & =\mu_{p} \lambda_{t}^{s} M C_{t} Y_{t}+\theta \beta E_{t} \Pi_{t+1}^{\nu} F_{t+1} \\
K_{t} & =\lambda_{t}^{s} Y_{t}+\theta \beta E_{t} \Pi_{t+1}^{\nu-1} K_{t+1} \\
1 & =\theta \Pi_{t}^{\nu-1}+(1-\theta)\left(\frac{K_{t}}{F_{t}}\right)^{\nu-1}
\end{aligned}
$$

where $K_{t}$ and $F_{t}$ are expressions reflecting the present value of future marginal costs and future production. These expressions emerge from the firm's optimality condition when resetting prices. Firms are owned by the saver households and therefore future marginal costs are discounted by the saver household's stochastic discount factor $\lambda_{t}^{s}$.

When prices are flexible, marginal costs are fixed and, to a log-linear approximation, $m c_{t}=0$. When prices are sticky, a log-linear approximation to the firm's pricing problem around a zero inflation steady state delivers the standard New Keynesian Phillips curve:

$$
\pi_{t}=\kappa m c_{t}+\beta E_{t} \pi_{t+1}
$$

where $\kappa=\frac{(1-\theta)(1-\theta \beta)}{\theta}$. 


\subsection{Equilibrium}

Asset market clearing requires that real saving equals real borrowing:

$$
\eta B_{t}+B_{t}^{g}=(1-\eta) D_{t}
$$

Combining the households' budget constraints and the government's budget constraint and firm profits implies an aggregate resource constraint of the form:

$$
Y_{t}=C_{t}+G_{t}
$$

Labor market clearing requires that labor supply equal labor demand:

$$
N_{t}=N_{t}^{\text {sup }}=\eta N_{t}^{b}+(1-\eta) N_{t}^{s}
$$

Definition 2. An equilibrium is a set of allocations $\left\{Y_{t}, N_{t}, C_{t}^{s}, C_{t}^{b}, N_{t}^{s}, N_{t}^{b}, \lambda_{t}^{s}, \lambda_{t}^{b}, B_{t}, F_{t}, K_{t}\right\}$, a price process for $\left\{W_{t}, \Pi_{t}, i_{t}^{d}, i_{t}^{b}, M C_{t}\right\}$, a fiscal policy $\left\{B_{t}^{g}, T_{t}, G_{t}, r e b_{t}\right\}$, and initial values for private debt $B_{-1}$ and public debt $B_{-1}^{g}$ that jointly satisfy the equilibrium conditions listed in the Appendix.

The fiscal policy considered consists of government purchases and tax rebates, as opposed to transfers. However, deficit-financing of these fiscal policies is equivalent to a transfer from saver to borrower households and back again.

Proposition 1. Consider an equilibrium under a deficit financed fiscal policy $\left\{B_{t}^{g}, T_{t}, G_{t}, r e b_{t}\right\}$. There exists a set of household-specific taxes $T_{t}^{b}$ and $T_{t}^{s}$ that implement the same equilibrium and satisfies a balanced budget: $G_{t}=\eta T_{t}^{b}+(1-\eta) T_{t}^{s}$

Proof. Since the saver household purchases the issuance of government debt, the saver's budget constraint may be expressed using the asset market clearing condition and substituting out for taxes using the government's budget constraint (10):

$$
\begin{aligned}
C_{t}^{s}+\frac{1}{1-\eta}\left(\eta B_{t}+B_{t}^{g}\right)= & W_{t} N_{t}^{b}+\Pi_{t}^{f}+\frac{1+i_{t-1}^{d}}{\Pi_{t}} \frac{1}{1-\eta}\left(\eta B_{t-1}+B_{t-1}^{g}\right) \\
& +B_{t}^{g}-\frac{1+i_{t-1}^{d}}{\Pi_{t}} B_{t-1}^{g}-G_{t}
\end{aligned}
$$


Rearranging, we may define saver specific tax $T_{t}^{s}$ :

$$
\begin{aligned}
C_{t}^{s}+\frac{\eta}{1-\eta} B_{t} & =W_{t} N_{t}^{b}+\Pi_{t}^{f}+\frac{1+i_{t-1}^{d}}{\Pi_{t}} \frac{\eta}{1-\eta} B_{t-1}-T_{t}^{s} \\
T_{t}^{s} & =\frac{\eta}{1-\eta}\left(B_{t}^{g}-\frac{1+i_{t-1}^{d}}{\Pi_{t}} B_{t-1}^{g}\right)+G_{t}
\end{aligned}
$$

For the borrower household, we may define the borrower specific tax $T_{t}^{b}=G_{t}-\left(B_{t}^{g}-\frac{1+i_{t-1}^{d}}{\Pi_{t}} B_{t-1}^{g}\right)$. It is readily verified that the household specific taxes satisfy the balanced budget constraint.

The proposition illustrates an equivalence relation between deficit-financing and transfers between agents. As the budget deficit increases, taxes fall for the borrower household and rise for the saver. A tax rebate represents a pure transfer from savers to borrowers despite the fact that both households receive the tax rebate. A deficit financed increase in purchases represents a combination of both transfers and purchases.

However, the transfer cannot be one way. As the debt is stabilized or decreased, the transfer reverses - borrowers make a transfer back to savers. Thus, in general, the converse of the proposition will not hold. A fiscal authority that can levy household specific taxes can implement a richer set of policies than a fiscal authority constrained to uniform taxation and deficit financing. For example, a one-way transfer cannot be implemented as a deficit-financed rebate. Moreover, the capacity of the fiscal authority to engineer transfers depends on the initial level of debt - with high levels of public debt, an increase in transfers requires an increase to higher debt levels where the overall transfer will be blunted by the size of interest payments.

\section{Case of No Wealth Effects on Labor Supply}

In this section, I examine the effect of purchases and transfers in a setting where household preferences or the structure of labor markets eliminate wealth effects on labor supply. The absence of wealth effects eliminates any effect of fiscal policy on aggregate supply. With prices set freely each period, firms' incentives to hire labor are not changed because neither its marginal costs nor its production technology are affected by the change in fiscal policy. When prices are changed only periodically, changes in fiscal policy will have an effect on aggregate demand. When prices are fixed, producers must meet demand at posted prices raising marginal costs. However, the monetary authority is always free to tighten interest rates and dampen demand so long as it is not constrained 
by the zero lower bound.

\subsection{Flexible Prices}

When producers are free to set prices each period, prices are a constant markup over marginal

costs. Since price is normalized to unity, marginal costs are constant: $\overline{M C}=\frac{1}{\mu_{p}}$ in all periods.

Proposition 2. If labor supply depends only on the wage for both households, then output and employment are determined independently of fiscal policy.

Proof. For each household, labor supply is determined by (2):

$$
W_{t}=v_{i}\left(N_{t}^{i}\right)
$$

for $i \epsilon\{s, b\}$. Under the assumptions in Section 3, the function $v$ is increasing. Therefore, it's inverse exists and combining the labor supply equation with labor market clearing:

$$
N_{t}=\eta v_{b}^{-1}\left(W_{t}\right)+(1-\eta) v_{s}^{-1}\left(W_{t}\right)
$$

Using the firm's production function (11) and labor demand condition (10), wages can be expressed in terms of employment:

$$
W_{t}=\alpha \overline{M C} N_{t}^{\alpha-1}
$$

Replacing wages, aggregate employment is determined independent of fiscal policy. The production function implies that output is also determined independent of fiscal policy.

Importantly, the irrelevance of fiscal policy holds irrespective of any of the properties of the credit spread and would continue to obtain in a model with other types of financial frictions (such as borrowing constraints) or a larger number of agents, so long as the labor supply relation holds for each agent. Using the economy's resource constraint (17), it follows that a tax rebate or transfer has no effect on aggregate consumption while an increase in government purchases is offset by an equivalent decrease in consumption. Significantly, the insights of the representative agent model are unchanged in the multiple agent setting. 


\subsection{Sticky Prices}

Under sticky prices, marginal costs are no longer constant and fiscal shocks will affect output and employment through the aggregate demand channel. However, monetary policy can also affect output and employment via the aggregate demand channel, and, since the feasible set of combinations of output and inflation is unchanged by the presence of credit spreads, monetary policy and fiscal policy are redundant.

To show that the Phillips curve is unchanged, I use a log-linear approximation to the equilibrium conditions to obtain the output inflation tradeoff. Under GHH preferences, the household's loglinearized labor supply conditions imply:

$$
w_{t}=\frac{1}{\nu} n_{t}^{i}
$$

for $i \epsilon\{s, b\}$. Aggregating using a log-linearized version of (18) and eliminating $w_{t}$ using (15):

$$
m c_{t}=n_{t}-y_{t}+\frac{1}{\nu} n_{t}
$$

Eliminating $n_{t}$ using the log-linearized production function (16) and using the equation for $m c_{t}$, the standard New Keynesian Phillips curve is obtained:

$$
\pi_{t}=\frac{\kappa}{\alpha}\left(1-\alpha+\frac{1}{\nu}\right) y_{t}+\beta E_{t} \pi_{t+1}
$$

The case of wage rigidity is simply the case of $\nu \rightarrow \infty$ :

$$
\pi_{t}=\frac{\kappa}{\alpha}(1-\alpha) y_{t}+\beta E_{t} \pi_{t+1}
$$

If monetary policy seeks to stabilize some combination of output and inflation, the targeting rule for optimal monetary policy will be unaffected by the presence of credit spreads or their variability. Formally, if the central bank chooses a path of $\pi_{t}, y_{t}$ to minimize a loss function of the form:

$$
\mathcal{L}=E_{0} \sum_{t=0}^{\infty} \beta^{t}\left(\pi_{t}^{2}+\lambda y_{t}^{2}\right)
$$


subject to the Phillips curve given above, then the target criterion is the standard one:

$$
\pi_{t}+\frac{\lambda}{\vartheta}\left(y_{t}-y_{t-1}\right)=0
$$

where $\vartheta$ is the slope of the Phillips curve. ${ }^{7}$ Importantly, the loss function here is ad hoc rather than microfounded - a second-order approximation of average utility in this economy would in general depend on differences in marginal utilities across households due to the presence of credit frictions (see Curdia and Woodford (2010) for an analysis of optimal monetary policy).

However, ignoring distributional concerns and assuming that monetary policy is primarily concerned about aggregate outcomes, the presence of credit spreads does not affect the set of feasible inflation and output combinations faced by the central bank. The primacy of monetary policy in determining the effect of fiscal shocks is similar to the conclusions in Woodford (2011). He showed that the government purchases multiplier could be larger or smaller than the neoclassical multiplier depending on how aggressively monetary policy responds to inflation.

Though, the inflation/output tradeoff is unchanged by credit spreads, the implementation of monetary policy will be affected. In general, setting the correct policy rate $i_{t}^{d}$ to implement a targeting criterion will require the monetary authority to take into account changes in the credit spread. A log-linear approximation to the household's Euler equations (1) and (3) - (4) and a log-linear approximation to the resource constraint (17) can be used to derive an aggregate IS curve:

$$
i_{t}^{d}=E_{t} \pi_{t+1}-\frac{1}{s_{c} \tilde{\sigma}}\left(y_{t}-g_{t}-E_{t}\left(y_{t+1}-g_{t+1}\right)\right)-\frac{s_{b} \sigma_{b}}{\tilde{\sigma}} \omega_{t}
$$

where $\omega_{t}$ is the credit spread, $\sigma_{b}$ is the borrower household's intertemporal elasticity of substitution, $\tilde{\sigma}$ is a weighted average of households intertemporal elasticity of substitution, $s_{b}$ is the share of borrower's consumption in total consumption in steady state, and $s_{c}$ is the share of private consumption in total output in steady state. Fiscal policy will directly affect the determination of interest rates through government purchases and also affect interest rates via the spread. So long as the zero lower bound on nominal interest rates is not binding, there exists a path of interest rates consistent with the target path of output and inflation set by the monetary authority. Any changes in fiscal policy can be accommodated by suitable adjustment of the interest rate. Since a path of output implies a path of employment, monetary policy and fiscal policy are redundant in

\footnotetext{
${ }^{7}$ The optimal targeting criterion features output instead of the output gap because the natural rate of output is simply steady state output.
} 
determining those quantities when the zero lower bound is not binding.

\subsection{Consumption and Saving Behavior}

Importantly, monetary policy and fiscal policy cannot achieve the same equilibrium allocations and are not equivalent in terms of the distribution of consumption between saver and borrower households. Fiscal policy may still have a role in achieving some distribution of consumption or level of private debt, and fiscal policy in general will have consequences for household wealth even if output is unchanged.

In the case of rigid real wages, setting $\chi_{n}=0$, and if prices are flexible or monetary policy stabilizes inflation (i.e. $\pi_{t}=0$ for all $t$ ), analytical solutions can be obtained for consumption of the borrower household:

$$
c_{t}^{b}=\beta_{a} a_{t-1}+\beta_{\tau} \operatorname{tax}_{t}
$$

where $a_{t-1}=b_{t-1}+i_{t-1}^{d}+\omega_{t-1}, \beta_{a}$ is the response of borrower consumption to the endogenous state variable $a_{t-1}$, and $\beta_{\tau}$ is the response of consumption to an exogenous tax increase. The state variable $a_{t-1}$ captures the total repayments that must be made by the borrower household in the current period (i.e. debt inclusive of interest payments).

When the debt elasticity of the credit spread is zero $\left(\chi_{b}=0\right)$, consumption responds minimally to temporary tax rebates with most of the proceeds used to pay down debt:

$$
\begin{aligned}
& \beta_{a}=-\bar{i} \frac{\bar{b}}{\bar{c}_{b}} \\
& \beta_{\tau}=-\frac{\bar{y}}{\bar{c}_{b}} \frac{\bar{i}}{1-\rho+\bar{i}}
\end{aligned}
$$

where $\rho$ is the persistence of the tax shock. If the borrower fully spent a tax rebate, then $\beta_{\tau}=\frac{\bar{y}}{\bar{c}_{b}}$. As can be seen, borrowers have a marginal propensity to consume of unity only if the rebate is permanent (i.e $\rho=1$ ). If $\rho=0$, then the multiplier is small because the steady state borrowing rate $\bar{i}$ is small. As the coefficient $\beta_{a}$ reveals, consumption is not particularly responsive to changes in household debt for small value of $\bar{i}$.

An explicit solution can also be obtained in the case that $\chi_{b} \rightarrow \infty$. The coefficients determining 
the response of consumption to repayments and taxes is given below:

$$
\begin{aligned}
& \beta_{b}=-(1+\bar{i}) \frac{\bar{b}}{\bar{c}_{b}} \\
& \beta_{\tau}=-\frac{\bar{y}}{\bar{c}_{b}}
\end{aligned}
$$

As can be seen, the response of borrower consumption to a decrease in taxes $\beta_{\tau}$ is the same as in the case of rule-of-thumb behavior. This coefficient does not depend on the persistence of the tax rebate. Likewise, borrower consumption is also strongly responsive to changes in debt repayments.

While the impact effect of a tax rebate is the same as in the case of rule-of-thumb behavior, temporary tax rebates have a larger dynamic multiplier due to effects on the evolution of the endogenous state variable $a_{t}$. Even a tax rebate that lasts only one period will have a persistent effect on borrower consumption by lowering future borrowing rates. While $b_{t}=0$ at all points in time when the debt elasticity is infinite, the credit spread falls in the future thereby crowding in consumption. This credit market channel is not present in models with rule-of-thumb agents or in models with simple borrowing constraints. Put differently, borrower consumption rises not only today but in future periods in response to a one-period transfer; in the rule-of-thumb case, borrower consumption would only rise in the periods when the transfer is received.

\section{Case of Wealth Effects on Labor Supply}

As the previous section illustrates, in the absence of wealth effects the transfer multiplier is either zero or entirely determined by the stance of monetary policy. Various parameters that govern the behavior of credit spreads are not directly relevant for the effect of fiscal policy on output.

In this section, I shift to the more conventional case of considering fiscal policy in the presence of wealth effects. In this case, analytical conclusions are less readily available and a quantitative analysis is required. These results show that, under standard parameterizations, the transfer multiplier is close to zero when prices are flexible and fairly modest when prices are sticky.

\subsection{No Credit Friction Benchmark}

To allow for wealth effects on labor supply, I consider standard preferences where the level of consumption affects agent's labor supply. To a log linear approximation, each agent's labor supply 
condition relates the wage to hours worked and consumption:

$$
w_{t}=\frac{1}{\varphi_{i}} n_{t}^{i}+\frac{1}{\sigma_{i}} c_{t}^{i}
$$

for $i \epsilon\{s, b\}$, where $\varphi_{i}$ is the Frisch elasticity of hours with respect to the wage and $\sigma_{i}$ is the elasticity of intertemporal substitution. The labor supply approximation given above holds irrespective of whether utility is separable in consumption and hours.

To examine how credit spreads affect fiscal multipliers, it is useful to first derive a benchmark with no credit frictions for comparison. In this setting, marginal utilities must be equalized across agents implying that $c_{t}^{s}=c_{t}^{b}=c_{t}$. Solving each agent's labor supply equation in terms of $n_{t}^{i}$ and aggregating labor using (18), an aggregate labor supply relation can be derived:

$$
\begin{aligned}
w_{t} & =\frac{1}{\tilde{\varphi}} n_{t}+\frac{1}{\tilde{\sigma}} c_{t} \\
\tilde{\varphi} & =l_{b} \varphi_{b}+\left(1-l_{b}\right) \varphi_{s} \\
\tilde{\sigma} & =\frac{\tilde{\varphi}}{\left(l_{b} \frac{\varphi_{b}}{\sigma_{b}}+\left(1-l_{b}\right) \frac{\varphi_{s}}{\sigma_{s}}\right)}
\end{aligned}
$$

where $l_{b}$ is the share of borrower's hours in total hours worked. Given this aggregate labor supply condition, the output multiplier can be obtained by solving for consumption and the wage in terms of output (assume flexible prices so that $m c_{t}=0$ ) and substituting into the resource constraint (17):

$$
y_{t}=\frac{\alpha}{\alpha+s_{c} \tilde{\sigma}\left(1-\alpha+\frac{1}{\tilde{\varphi}}\right)} g_{t}
$$

where $s_{c}$ is the share of consumption in GDP and $\tilde{\varphi}$ is the average Frisch elasticity and $\tilde{\sigma}$ is a weighted intertemporal elasticity of substitution. Government spending increases output via a negative wealth effect, but the government spending multiplier is necessarily less than one. Transfers and deficit-financing have no affect on output. Aside from differences in the definition of the intertemporal elasticity of substitution and the Frisch elasticity, this expression for output is the same as would obtain in a representative agent setting.

The no credit frictions case also admits a representation for the Phillips curve. Eliminating $m c_{t}$ using the labor demand equation (15) and eliminating $n_{t}$ using the production function (16) 
provides a Phillips curve representation:

$$
\pi_{t}=\kappa\left(w_{t}+\frac{1-\alpha}{\alpha} y_{t}\right)+\beta E_{t} \pi_{t+1}
$$

Using the resource constraint (17) to eliminate $c_{t}$ and the production function, wages can be expressed in terms of output and government purchases. Replacing the wage in the Phillips curve provides the relationship between output and inflation:

$$
\pi_{t}=\frac{\kappa}{\alpha}\left(\frac{1}{\tilde{\varphi}}+\frac{1}{s_{c} \tilde{\sigma}}+1-\alpha\right) y_{t}-\frac{\kappa}{s_{c} \tilde{\sigma}} g_{t}+\beta E_{t} \pi_{t+1}
$$

An increase in government purchases shifts back the Phillips curve by increasing labor supply and lowering wages - purchases raise the natural rate of output. Transfers and tax rebates have no effect on the Phillips curve.

\section{$5.2 \quad$ Flexible Prices}

In the case of a model with credit spreads, the labor supply relations can be solved for consumption

$c_{t}^{i}$ in terms of the wage $w_{t}$ and hours worked $n_{t}^{i}$ for each agent. Substituting into the resource constraint and eliminating the wage using (15), output can be expressed in terms of purchases and hours worked by each agent:

$$
\begin{aligned}
y_{t}= & \frac{\alpha}{\alpha+s_{c} \bar{\sigma}(1-\alpha)} g_{t} \\
& -\frac{s_{c}}{\alpha+s_{c} \bar{\sigma}(1-\alpha)}\left(\frac{s_{b} \sigma_{b}}{\varphi_{b}} n_{t}^{b}+\frac{\left(1-s_{b}\right) \sigma_{s}}{\varphi_{s}} n_{t}^{s}\right)
\end{aligned}
$$

where $\bar{\sigma}=s_{b} \sigma_{b}+\left(1-s_{b}\right) \sigma_{s}$ is a weighted average elasticity of intertemporal substitution and other parameters as defined earlier.

The expression for output can be further simplified by solving for $n_{t}^{b}$ from labor market clearing (18), giving output as a function of government purchases and the saver household's labor supply:

$$
\begin{aligned}
y_{t}= & \frac{\alpha}{\alpha+s_{c} \bar{\sigma}(1-\alpha)+s_{c} \frac{s_{b} \sigma_{b}}{l_{b} \varphi_{b}}} g_{t} \\
& +\frac{\alpha s_{c}}{\alpha+s_{c} \bar{\sigma}(1-\alpha)+s_{c} \frac{s_{b} \sigma_{b}}{l_{b} \varphi_{b}}}\left(\frac{\left(1-l_{b}\right)}{l_{b}} \frac{s_{b} \sigma_{b}}{\varphi_{b}}-\frac{\left(1-s_{b}\right) \sigma_{s}}{\varphi_{s}}\right) n_{t}^{s}
\end{aligned}
$$

Proposition 3. Transfers and the means of financing any government expenditure have no effect 
on output and employment if:

1. Preferences are linear in hours worked as in Hansen (1985) and Rogerson (1988)

2. Labor supply by households is coordinated: $n_{t}^{s}=n_{t}^{b}$

3. Preferences satisfy the following condition:

$$
\frac{1-l_{b}}{l_{b}} \frac{\varphi_{s}}{\varphi_{b}}=\frac{1-s_{b}}{s_{b}} \frac{\sigma_{s}}{\sigma_{b}}
$$

Proof. In the first case, as the Frisch elasticities $\varphi_{s}=\varphi_{b} \rightarrow \infty$, the coefficient on the second term in the expression for output goes to zero, and output is only affected by purchases. In the second case, hours worked by the saver hours equal aggregate hours: $n_{t}^{s}=n_{t}=\frac{1}{\alpha} y_{t}$ and output is solely a function of purchases. In the last case, the coefficient on hours of the saver household is zero.

The proposition illustrates that, even with wealth effects on labor supply, transfers and deficitfinancing may have little effect on output or employment. The deviations from the frictionless benchmark stem solely from the second term in the output expression. If households are sufficiently homogenous - that is, if household do not differ appreciably in underlying parameters and shares of consumption and hours, the coefficient on the second term is likely to be small. If this coefficient is positive, fiscal policies that strengthen the negative wealth effect on the saver household will boost the output multiplier relative to the benchmark case. In particular transfers away from the saver household should boost multipliers. However, if the coefficient is negative, fiscal policies that boost the negative wealth effect on borrowers will increase multipliers.

\subsection{Sticky Prices}

In the case of sticky prices, fiscal policy has both a supply effect that reduces marginal costs and an demand effect that raises marginal costs. Monetary policy does not face a stable Phillips curve relation between inflation and output, and the choice of fiscal policy may shift the Phillips curve in favorable or unfavorable ways. As before, the Phillips curve can be expressed in terms of both output and wages:

$$
\pi_{t}=\kappa\left(w_{t}+\frac{1-\alpha}{\alpha} y_{t}\right)+\beta E_{t} \pi_{t+1}
$$

However, unlike the frictionless case, wages cannot generally be expressed in terms of aggregate output. 
Table 2: Calibration summary

\begin{tabular}{lcclcc} 
Parameter description & Parameter & Value & Parameter Description & Parameter & Value \\
\hline \hline Intertemporal elasticity & $\sigma_{i}$ & 1 & Deposit rate & $\bar{i}_{d}$ & $1.02^{0.25}$ \\
Frisch elasticity & $\varphi_{i}$ & 2 & Borrowing rate & $\bar{i}_{b}$ & $1.06^{0.25}$ \\
Calvo parameter & $\theta$ & 0.75 & Borrower share & $\eta$ & $50 \%$ \\
Markup & $\mu_{p}$ & 0.25 & Debt elasticity & $\chi_{b}$ & 0.1 \\
Wage bill & $\bar{N} / \bar{Y}$ & 0.70 & Income elasticity & $\chi_{n}$ & 0 \\
Gov't purchases & $\bar{G} / \bar{Y}$ & 0.20 & Taylor rule (inflation) & $\phi_{\pi}$ & 1.5 \\
Debt/GDP & $\bar{B}_{g} / \bar{Y}$ & 2 & Taylor rule (output) & $\phi_{y}$ & 0.25 \\
Household debt & $\bar{B} / W N_{b}$ & 4 & Fiscal rule & $\phi_{b}$ & 0.2
\end{tabular}

In the cases considered in the previous proposition, transfers have no effect on aggregate output and therefore the Phillips curve can be represented solely in terms of inflation, output, and government purchases as in the benchmark case. Since transfers do not shift the Phillips curve, credit spreads do not affect the Phillips curve and the output-inflation tradeoff is unchanged. As before, households labor supply equations can be aggregated into an aggregate labor supply equation:

$$
w_{t}=\frac{1}{s_{c} \tilde{\sigma}}\left(y_{t}-g_{t}\right)+\frac{1}{\tilde{\sigma}}\left(\frac{s_{b} \sigma_{b}}{\varphi_{b}} n_{t}^{b}+\frac{\left(1-s_{b}\right) \sigma_{s}}{\varphi_{s}} n_{t}^{s}\right)
$$

where the first term gives the wealth effect on labor supply and the second term gives the substitution effect. Because government purchases act to directly lower the wage while transfers cause offsetting movements in hours between households, purchases have a greater downward effect on wages. A reduction in wages will provide the monetary authority with a more favorable output and inflation tradeoff and allow for a less restrictive monetary policy. In this sense, one can conjecture that purchases may be better than transfers for boosting output and employment since they allow monetary policy greater scope for accommodation.

\subsection{Calibration}

As I have shown, in the presence of wealth effects on labor supply, fiscal policy will feature both supply and demand channels. To assess the degree to which credit frictions matter, I calibrate the model with wealth effects and examine the effect of deficit-financed purchases and tax rebates. While each deficit-financed policy can be expressed as a balanced budget combination of purchases and transfers, the deficit-financed policies considered here are closest to fiscal policy in practice and 
avoid issues of incentive compatibility. ${ }^{8}$

The baseline calibration assumes standard separable utility function of the form

$$
U(C, N)=\frac{C^{1-\sigma^{-1}}}{1-\sigma^{-1}}-\nu N^{1+\varphi^{-1}}
$$

with standard values for the Frisch elasticities and intertemporal elasticities of substitution. In the baseline calibration these values are equal across agents with $\varphi_{b}=\varphi_{s}=2$ and $\sigma_{b}=\sigma_{s}=1$. In steady state, output $\bar{Y}$ is normalized to 1 and the disutility of labor supply for each household $\nu_{s}$ and $\nu_{b}$ is set to ensure that each household supplies labor such that $\bar{N}_{b}=\bar{N}_{s}=1$. The markup due to monopolistic competition is set at $25 \%$ and the labor share $\alpha$ is set to ensure that the wage bill is equal to $70 \%$ of GDP, consistent with U.S. data. The Calvo parameter $\theta$ is set to 0.75 so that firms change prices every 4 quarters on average. The rates of time preference $\beta$ and $\beta_{b}$ are set to target an annual deposit rate of $2 \%$ and an annual borrowing rate of $6 \% .^{9}$ The disutilities of labor supply, the rates of time preference, and the markup do not enter the log-linearized equilibrium conditions and, therefore, do not affect the dynamics of the model. In steady state, the consumption of the borrower household is less than that of the saver household since the saver household earns both wage income and profits from the firm. Government spending is $20 \%$ of GDP in steady state. The steady state public debt is $50 \%$ of GDP consistent with recent U.S. levels. The response parameter in the fiscal rule $\phi_{b}$ is close to the rule used in Gali, Lopez-Salido and Valles (2007), which is based on VAR estimates for U.S. data. In steady state, the household debt for the borrower household is equal to annual household income consistent with data on household wealth from the Survey on Consumer Finances.

The nonstandard parameters for the model include the credit spread parameters $\chi_{b}$ and $\chi_{n}$ that control, respectively, the endogenous response of spreads to private sector debt and expected borrower income and the share of borrower households $\eta$ in the economy. In the baseline case, I will consider a debt-elastic spread such that $\chi_{b}=0.1$ and $\chi_{n}=0$ - a calibration that implies a $1 \%$ increase in debt raises spreads by roughly 50 basis points. In general, a regression of spreads on measures of indebtedness and income in aggregate data is unlikely to accurately estimate these elasticities given that common shocks may induce a comovement of income and spreads even though $\chi_{n}=0$. As shown in Section 6, the financial shock $z_{t}$ causes income and spreads to comove even

\footnotetext{
${ }^{8}$ In the case of household specific taxes and transfers, household have an incentive to mask their type and represent themselves as borrowers or lenders based on the proposed fiscal policy.

${ }^{9}$ The implied credit spread is somewhat conservative to take into borrowing cost for collateralized household loans like mortgages. In any case, these rates of time preference do not affect the log-linearized dynamics.
} 
Figure 1: Deficit-financed purchases and tax cuts
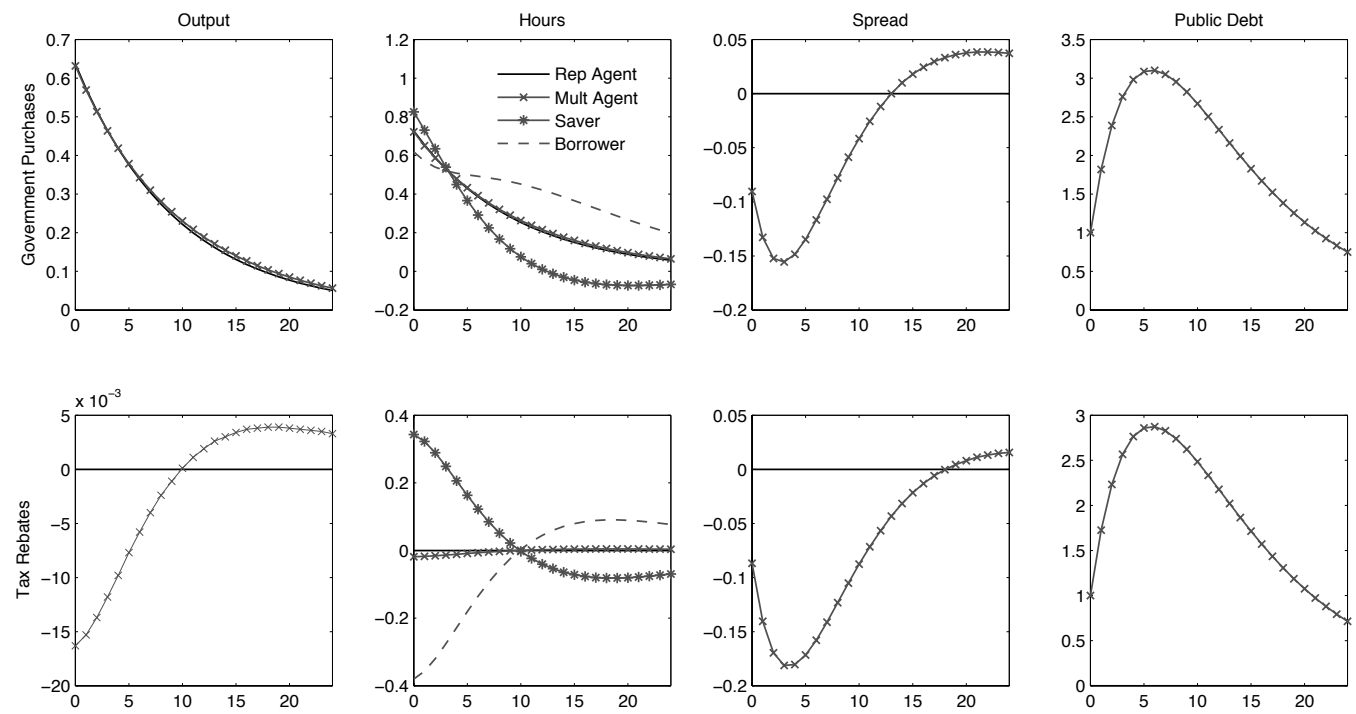

with $\chi_{n}=0$. As it turns out, these credit spread elasticities have little effect on the experiments here suggesting that spreads may have a fairly small effect on fiscal policy transmission away from the zero lower bound. The share of borrower household $\eta$ is set to $50 \%$ as in Curdia and Woodford (2010); this parameter has no obvious analogue in the data and is selected conservatively to minimize heterogeneity. The calibration values are summarized in Table 2.

\subsection{Fiscal Policy Experiments and Sensitivity}

The first experiment in Figure 1 considers the effect of a 1\% of GDP increase in government purchases (top panel) and a 1\% of GDP increase in tax rebates (bottom panel), each with a persistence of $\rho=0.9$. The figure also shows the response of the no credit frictions economy with parameters as defined in Section 5.1. The fiscal authority runs a budget deficit and taxes follow a fiscal rule - taxes adjust upwards to return the public debt to its steady state level. Prices are reset each period and, therefore, firm markups are constant.

In this environment, the effect of purchases and rebates is driven by wealth effects on labor supply. Under the baseline calibration where the Frisch elasticity and intertemporal elasticity of substitution are equal, the only source of heterogeneity is the share of borrower consumption $s_{b}<\frac{1}{2}$ since the borrower household pays interest to the intermediary and does not receive any profits from firms. ${ }^{10}$ Under this calibration, the coefficient on saver's hours (in the output expression Section 5.2)

\footnotetext{
${ }^{10}$ Steady state government purchases are financed by a tax on patient households to reduce differences in steady
} 
Figure 2: Alternative credit spread elasticities
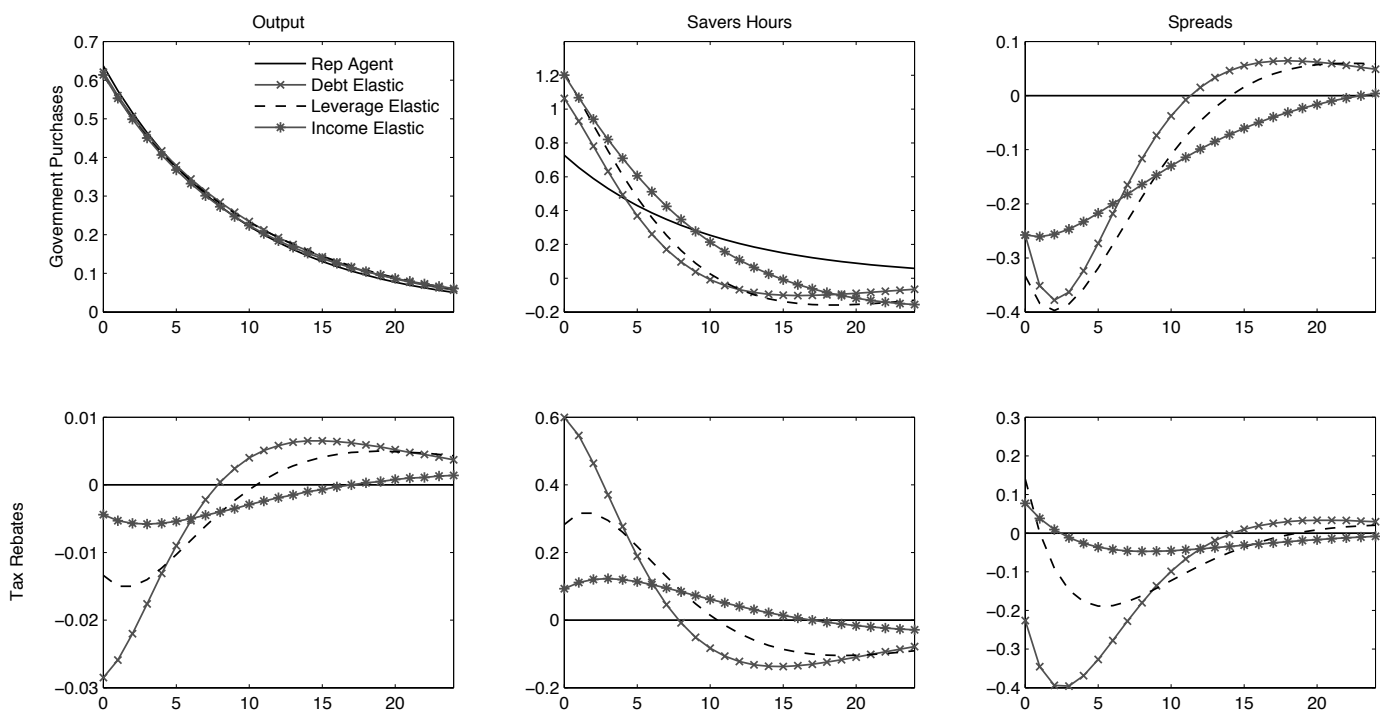

is negative. As a result, the tax rebate multiplier is slightly negative - the fall in hours worked by the borrower household is not fully offset by the rise in hours by the saver household. The transfer acts to dampen aggregate incentives to work. Likewise, the government purchases multiplier on output is slightly lower than the frictionless benchmark since the labor supply effects for the borrower are dampened by the increase in the deficit. As the second column shows, the response in hours worked by each household is quite different reflecting the transfer component of fiscal policy. However, these movements wash out in the aggregate - the difference in aggregate hours between the benchmark model and the model with credit frictions is miniscule. The dynamics of public debt illustrate the degree of transfers from the saver household - periods of increasing debt represent net transfers to borrowers, while periods of stabilizing and falling debt represent transfers from borrowers back to savers. Importantly, these policies do not imply the same debt dynamics since changes in the interest rate have an effect on debt accumulation in a calibration with a positive steady state level of debt. With zero debt and a linear approximation, both policies would imply the same path of the public debt. Government purchases have larger output multipliers than tax rebates simply because purchases have a larger wealth effect on labor supply. Output and employment rise as the wage falls due to the increased willingness of both households to work.

Figures 2 and 3 examine how sensitive these results are to the credit spread elasticities $\chi_{b}$ and

state levels of consumption (through a tax on capital holdings). However, it is assumed that both household pay taxes proportional to their size in the economy to finance government purchases in excess of steady state levels. In steady state, $\bar{C}_{s} / \bar{C}_{b} \sim 1.3$. 
Figure 3: Alternative intertemporal elasticities of substitution
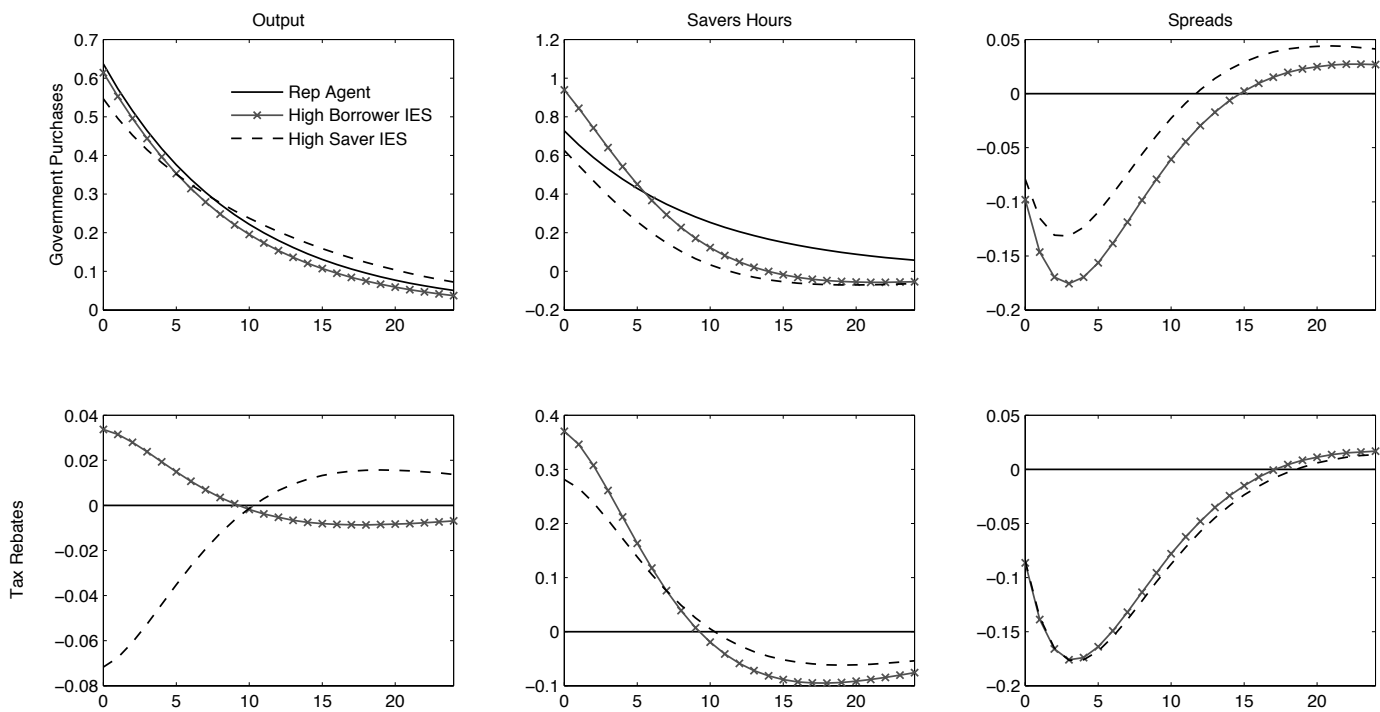

$\chi_{n}$ and to heterogeneity in wealth effects across households by adjusting the relative intertemporal elasticities of substitution. Figure 2 show that different models of the spread have little effect on the deviations of output multipliers from the benchmark case - in particular that tax rebate multiplier is still negative and close to zero. Figure 2 considers three cases: debt elastic spreads $\left(\chi_{b}=0.5, \chi_{n}=0\right)$, leverage elastic spread $\left(\chi_{b}=\chi_{n}=0.5\right)$, and income elastic spread $\left(\chi_{b}=0.1, \chi_{n}=0.5\right)$. In all cases, the purchases and rebate multipliers deviates by less than $5 \%$ from the frictionless benchmark. In each case, the behavior of hours and spreads differs, but the aggregate effect on output, hours, wages, and consumption are all close to the frictionless benchmark. The second column shows that saver's hours respond strongly to the tax rebate shock, but the borrower's response almost fully offsets this rise in hours resulting in little net effect.

Figure 3 examines the effect of variations in the relative intertemporal elasticity of substitution holding the average intertemporal elasticity fixed at $\tilde{\sigma}=1$ where $\tilde{\sigma}$ is as defined in Section 5.2. In the case of "high borrower elasticity," wealth effects for the borrower household are diminished by choosing an intertemporal elasticity of substitution three times higher than that of the saver household. Alternatively, in the case of "high saver elasticity," the borrower household has an intertemporal elasticity of substitution one-third the size of the saver household and, therefore, the borrower's labor supply is more sensitive to changes in wealth. When the borrower household exhibits smaller wealth effects, the tax rebate multiplier becomes positive. ${ }^{11}$ Savers respond to the

\footnotetext{
${ }^{11}$ Relatively stronger wealth effects for saver household could be justified on the grounds that wealthier households
} 
Figure 4: Deficit-financed purchases and tax rebates under a Taylor rule
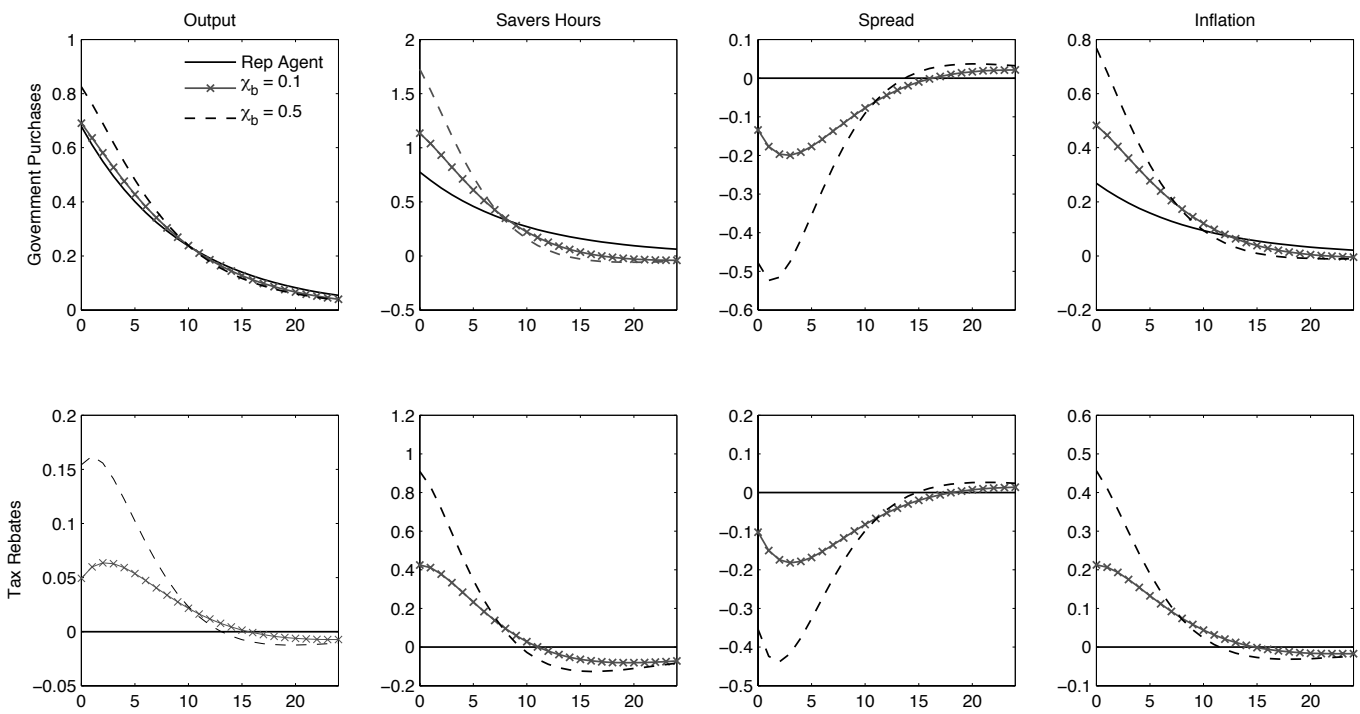

negative wealth shock by working harder while borrowers reduce their hours but by less than in the baseline case. As a result, aggregate hours and output rises. The opposite occurs in the case of high saver elasticity for the same reason. As before, the government purchases multiplier is an order of magnitude higher than the tax rebate multiplier simply because of the stronger wealth effects on aggregate labor supply under purchases.

Figure 4 relaxes the assumption of flexible prices and examines the effect of an increase in purchases and tax rebates when monetary policy follows a Taylor rule. To ensure that a tax rebate is expansionary, the calibration used in Figure 4 assumes the case of a high borrower elasticity of intertemporal substitution - that is, $\sigma_{b} / \sigma_{s}=3$. As the experiment demonstrates, fiscal multipliers rise sizably under an operative aggregate demand channel. Moreover, a more elastic credit spread raises multipliers further - when the elasticity of the spread to debt rises from $\chi_{b}=0.1$ to $\chi_{b}=0.5$, the output multiplier on purchases rises from 0.69 to 0.82 . Likewise, the output multiplier for tax rebates rises from 0.05 to 0.15 . The falling credit spread dampens the transmission of monetary policy as the rise in the deposit rate is not fully incorporated into the borrowing rate (since spreads are falling). However, as noted earlier, bigger multipliers come only at the cost of higher inflation as seen in the last column. This rise in inflation is due to the fact that the Phillips curve has not shifted, and larger multipliers are the product of an accommodative stance of monetary policy. As before, the purchases multiplier is an order of magnitude larger than the transfers multiplier. 
However, if monetary policy responds asymmetrically to different fiscal shocks, it is possible to obtain cases where the tax rebate multiplier is as high or higher than the purchases multiplier. Finally, purchases are preferred to tax rebates in the sense that purchases generate a larger rise in output and employment for a given amount of inflation. The negative wealth effect of purchases raises labor supply, reduces marginal costs, and improves the Phillips curve tradeoff.

\section{Zero Lower Bound}

In this section, I examine how credit spread shocks may cause the zero lower bound to bind and consider the effect of government purchases and transfers on output and consumption. Consistent with evidence from representative agent models, the government purchases multiplier is above unity at the zero lower bound. Additionally, transfers (implemented by tax rebates) may be similarly effective as purchases in stabilizing output and consumption. The choice among policies depends on the endogenous feedback of debt and income on the credit spread, particular the debt elasticity of the credit spread.

Representative agent models typically rely on preference shocks or other reduced form shocks to the natural rate of interest to cause the zero lower bound to bind. However, in a model with multiple agents, disruptions to the financial system that raise the credit spread may also cause the zero lower bound to bind. As shown in Section 4, an aggregate IS equation can be obtained by summing the agent's Euler equations:

$$
i_{t}^{d}=E_{t} \pi_{t+1}-\frac{1}{s_{c} \tilde{\sigma}}\left(y_{t}-g_{t}-E_{t}\left(y_{t+1}-g_{t+1}\right)\right)-\frac{s_{b} \sigma_{b}}{\tilde{\sigma}} \omega_{t}
$$

Any shock to the credit spread $\omega_{t}$ will drive down the interest rate when monetary policy seeks to maintain $y_{t}=\pi_{t}=0$, and for sufficiently large shocks, the interest rate will fall to the zero bound. The reduced form credit spread depends endogenously on debt and borrower income and, exogenously, on a financial shock. Any underlying shock that drives up debt and/or decreases borrower income may reduce the deposit rate, but I will consider an exogenous financial shock as the shock that causes the zero lower bound to bind.

The special case of real wage rigidity and a credit spread with zero debt elasticity $\left(\chi_{b}=0\right)$ illustrates the role of purchases versus transfers in determining output and inflation. Under these conditions, output and inflation are solely determined by the Phillips curve and the intertemporal 
IS curve:

$$
\begin{aligned}
& \pi_{t}=\kappa \frac{(1-\alpha)}{\alpha} y_{t}+\beta E_{t} \pi_{t+1} \\
& y_{t}=E_{t}\left(y_{t+1}\right)+E_{t}\left(g_{t+1}-g_{t}\right)-s_{c} \bar{\sigma}\left(i_{t}^{d}-E_{t} \pi_{t+1}\right)-s_{c} s_{b} \sigma_{b}\left(z_{t}-\frac{\chi_{n}}{\alpha} E_{t} y_{t+1}\right)
\end{aligned}
$$

where the credit spread is replaced by the log-linearized version of (9). By setting the debt elasticity of the spread to zero, the law of motion for debt and the distribution of consumption between saver and borrower households is decoupled from the determination inflation and output. Consider zero lower bound episode that is caused by a temporary increase in $z_{t}$ to $\bar{z}$ that reverts to zero with probability $1-\rho$ in each period causing the zero lower bound to bind: $i_{t}^{d}=-\bar{r}$. Given the absence of a state variables, this two-equation system is forward-looking and multipliers may be computed explicitly as in Woodford (2010):

$$
\begin{aligned}
y_{z l b} & =\nu_{g} \bar{g}-\zeta \\
\nu_{g} & =\frac{(1-\rho)(1-\beta \rho)}{(1-\beta \rho)\left(1-\rho-s_{c} s_{b} \sigma_{b} \rho \frac{\chi_{n}}{\alpha}\right)-s_{c} \bar{\sigma} \frac{\kappa}{\alpha}(1-\alpha) \rho} \\
\zeta & =\frac{s_{c}(1-\rho)\left(s_{b} \sigma_{b} \bar{z}-\overline{\sigma r}\right)}{(1-\beta \rho)\left(1-\rho-s_{c} s_{b} \sigma_{b} \rho \frac{\chi_{n}}{\alpha}\right)-s_{c} \bar{\sigma} \frac{\kappa}{\alpha}(1-\alpha) \rho}
\end{aligned}
$$

The constant term gives the decrease in output in the absence of any policy intervention and under the assumption that monetary policy ensures that $y_{t}=\pi_{t}=0$ after the financial shock dissipates. $^{12}$ If the credit spread does not respond (or responds weakly) to changes in private debt, transfers and tax rebates have no effect on output and inflation and are ineffective as fiscal stimulus. Government purchases are effective in counteracting the effects of a financial shock, but the mechanism is essentially the same as any representative agent model of government purchases at the zero lower bound. The means of financing the increase in purchases are irrelevant. In fact, the multiplier is identical to the multiplier in Woodford (2011) except for the endogenous effect of output on the spread through $\chi_{n}$. When $\chi_{n}>0$, the multiplier on government purchases is higher as is the negative effect of the financial shock.

The polar case of an infinite debt elasticity does not lend itself to an analytical solution at the zero lower bound like $\chi_{b}=0$, but it is still possible to show how a higher debt elasticity raises the transfer multiplier. In particular, with rigid real wages and a labor share equal to unity,

\footnotetext{
${ }^{12} \mathrm{~A}$ solution exists only if the persistence of the financial shocks is such that the denominator of $\nu_{g}$ is positive.
} 
consumption by the borrower is given by the following expression:

$$
c_{t}^{b}=\frac{\bar{w} \bar{n}_{b}}{\bar{c}_{b}} y_{t}+\frac{\bar{b}}{\bar{c}_{b}} \frac{1}{1+\chi_{b}} a_{t}-(1+\bar{i}) \frac{\bar{b}}{\bar{c}_{b}} a_{t-1}-\frac{\bar{y}}{\bar{c}_{b}} \operatorname{tax}_{t}
$$

As the debt elasticity approaches infinity, the coefficient on $a_{t}$ goes to zero and the borrower's consumption depends positively on current output and negatively on taxes. A tax cut will directly boost household consumption and indirectly boost consumption by raising income (the first term in the expression). This mechanism is borne out in the quantitative analysis that follows.

These simple example highlights how transfers operate through the credit spread. To the extent that transfers decrease the credit spread by lowering household indebtedness, transfers will have a positive multiplier. This analysis suggests that deficit-financed government purchases will be preferred to purchases financed by taxes because the transfer component of the policy further reduces credit spreads; indeed, this result holds in the numerical examples considered in the next section. Moreover, since transfers only operate through the spread, the transfers multiplier is unlikely to exceed the government purchases multiplier unless purchases worsen the rise in spreads. In the calibrated examples considered next, purchases reduce private sector indebtedness and the credit spread.

The experiment here roughly attempts to capture the type of disruption experienced in the U.S. after the collapse of Lehman Brothers in 2008. The model and calibration are the same as considered in the previous section, however, for simplicity, that monetary authority is assumed to follow perfect inflation stabilization $\pi_{t}=0$ for all periods after the zero lower bound ceases to bind. While monetary policy may, in principle, mitigate the effects of the financial shock by committing to higher future inflation (as discussed extensively in Eggertsson and Woodford (2003)), I assume that time inconsistency diminishes the effectiveness of these commitments. Additionally, steady state public debt is assumed to be zero to ensure that each policy implies the same path for the public debt (to a linear approximation) and the shock generates no movements in debt or taxes beyond the dynamics implied by the fiscal rule.

Figure 5 shows the effect of a financial shock that raises (annualized) credit spreads 16 percentage points. ${ }^{13}$ The model is solved using the solution algorithm described in the appendix of Eggertsson and Woodford (2003) and the financial shock is assumed dissipate with a persistence of $\rho=0.8 .^{14}$

\footnotetext{
${ }^{13}$ The actual rise in the credit spread is larger because of the endogenous component due to the increase in private sector debt.

${ }^{14}$ Note that we do not assume that the shock reverts with some probability in each period, but rather the shock decays geometrically with $\rho=0.8$. This assumption simplifies the solution but also allows fiscal policy to have an
} 
Figure 5: Financial shock with flexible wages
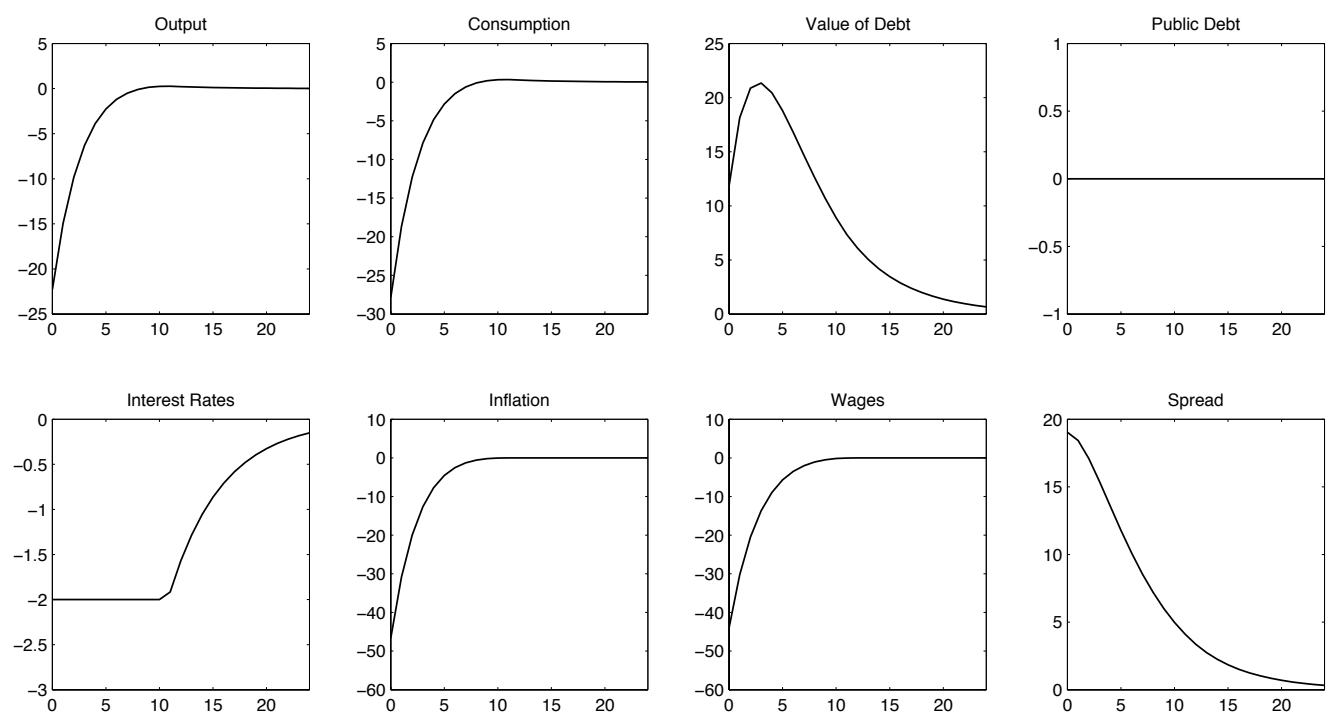

The time at which the economy exits the zero lower bound depends on the endogenous behavior of private sector debt and the value of the elasticity $\chi_{b}$. For high elasticities, a faster rate of deleveraging will cause the credit spread to fall faster hastening the exit from the zero lower bound. However, as shown in Figure 5, agents actually increase their debt loads since the elasticity of the spread to debt is fairly low $\left(\chi_{b}=0.1\right)$.

\subsection{No Policy Intervention}

A 16 percentage point financial shock raises credit spreads by 20 percentage points and leads to a very large fall in output and consumption in excess of $20 \%$. The negative wealth effect drives down wages $40 \%$ and the fall in demand and wages combines to cause a very steep deflation. The zero lower bound episode lasts for 10 quarters or two and half years, and rates gradually normalize as debt and spreads fall. After the ZLB ceases to bind, inflation remains at zero and output is marginally positive due to wealth effects that keep wages lower than their steady state level.

Given the role of wealth effects in leading to a counterfactually sharp fall in wages and inflation, I also consider a similar shock in a model without wealth effects on labor supply. In the presence of a perfectly rigid wage, changes in household wealth have no effect on output or employment. Figure 6 provides the impulse responses to a larger 20 percentage point financial shock. ${ }^{15}$ Under rigid wages,

effect on when the economy exits the zero lower bound episode.

${ }^{15}$ The large size of the credit spread shock is made to target a drop in output of roughly the magnitude experienced 
Figure 6: Financial shock with perfectly rigid real wages
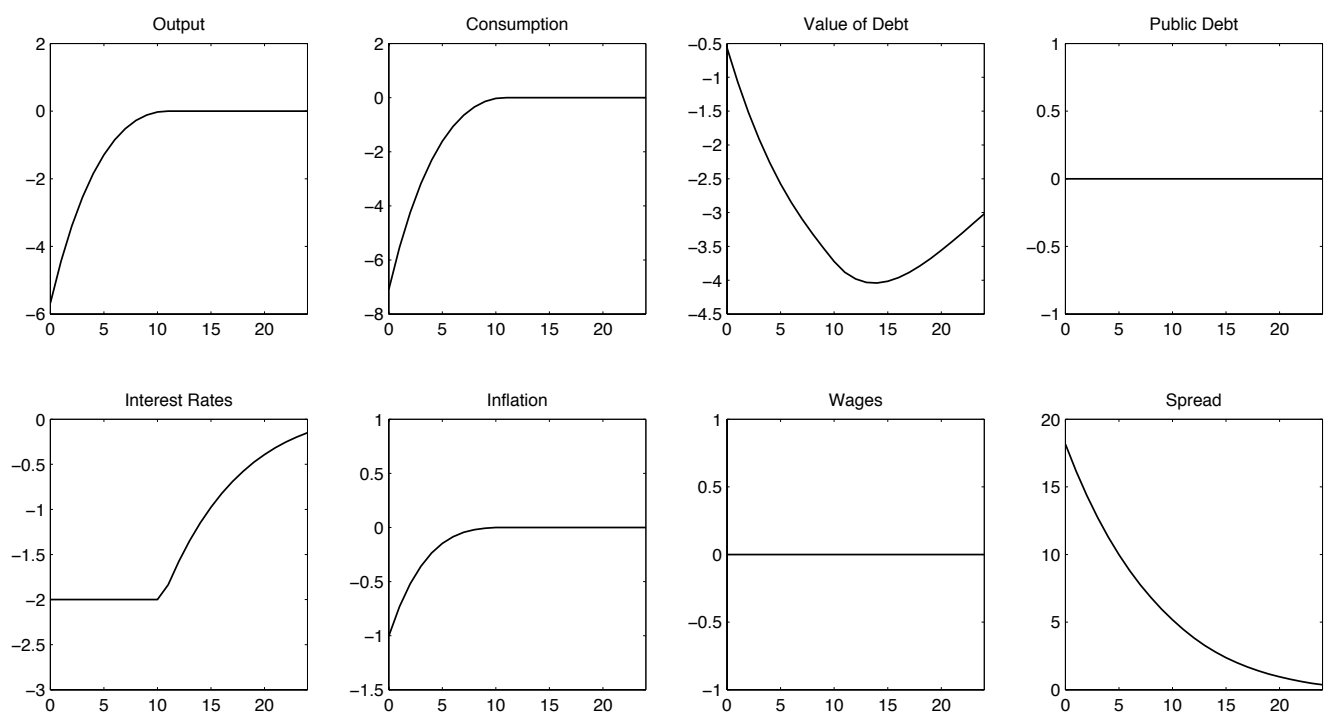

the fall in output and inflation are significantly dampened with output falling $6 \%$ and (annualized) inflation falling $1 \%$ on impact - values that are comparable to the U.S. output and inflation response in the fourth quarter of 2008. The rigid wage model has the advantage of delivering more realistic quantitative responses for output and inflation. The zero lower bound ceases to bind in 12 quarters and, since the Phillips curve is independent of spreads, output, consumption and inflation jump to their steady state levels. Households deleverage throughout the crisis period and only begin to releverage after three years; interest rates remain below their steady state level for the entire period of 24 quarters or six years.

\subsection{Policy Intervention}

I consider deficit financed fiscal policies where the intervention ends as soon as the zero lower bound ceases to bind. Fiscal policy may either raise government purchases or reduce taxes by some level so long as the zero lower bound binds. The choice of a flexible or rigid wage has significant implications for the efficacy of policy. Figure 7 shows the effect of a 1\% of GDP increase in government purchases and a 1\% decrease in taxes for all periods that the zero lower bound binds. Small policy interventions have very large effects relative to no intervention. For both government purchases and tax rebates, the economy exits the zero lower bound within a year instead of 2.5 years. Under the tax rebate, the fall in output is $2.5 \%$ versus a $22 \%$ fall absent intervention. For in the US during the Great Recession. 
Figure 7: Deficit-financed purchases and tax rebates in flexible wage model
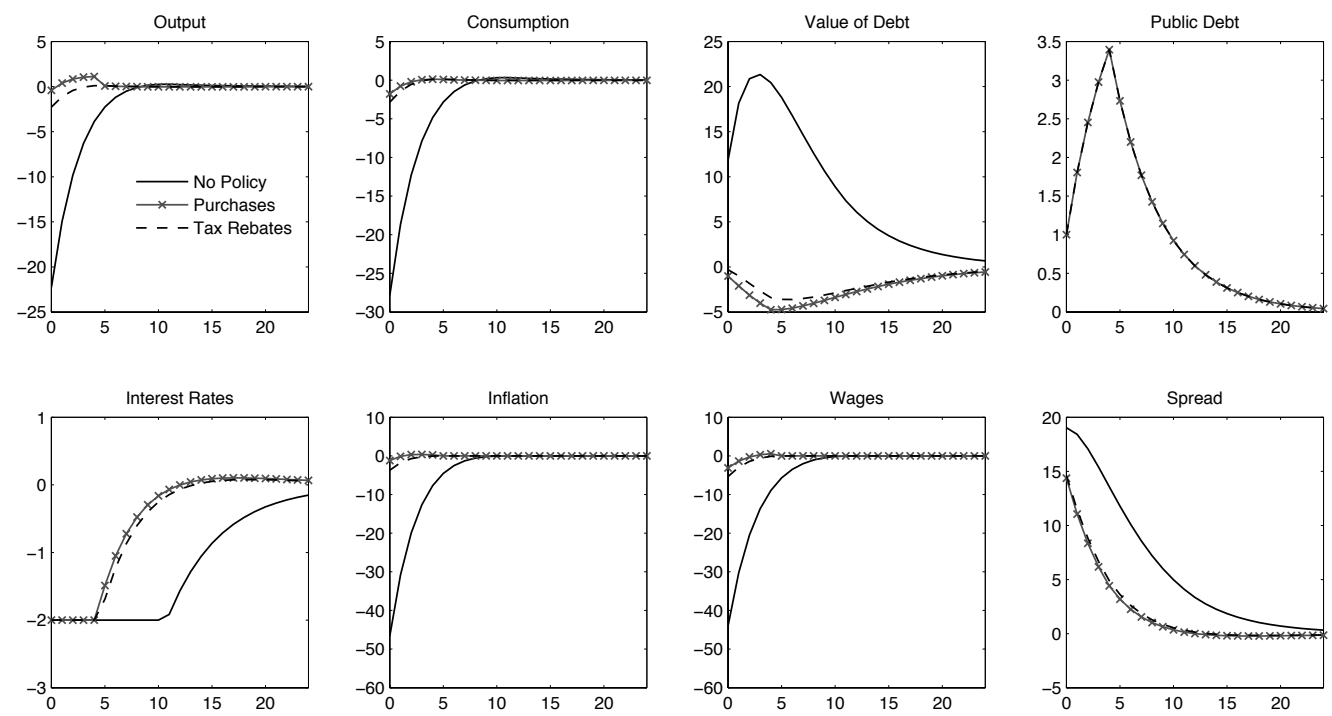

government purchases, the fall in output only lasts a quarter with output falling by only $0.5 \%$. Instead of continuing to increase leverage, households deleverage between $3 \%$ and $5 \%$ and the intervention reduces the rise in spreads by $1 / 3$. Deficit-financed purchases are preferred to tax rebates both in terms of output and consumption. Purchases act more directly to raise output and inflation, reducing the real interest rate faced by saver households and "crowding-in" consumption.

Figure 8 shows the much more limited effect of a $1 \%$ increase in purchases and tax rebates in the rigid wage model. Both policies are successful in boosting both output and consumption relative to a policy of inaction, but these policies carry much smaller multipliers than in the case of flexible wages. Government purchases limit the fall in output to $3.8 \%$ and rebates limit the fall in output to $5.3 \%$ relative to the $5.7 \%$ fall absent any intervention. Purchases, once again, act more directly to boost inflation and raise the consumption profile of the saver household while the borrowers consumption path is a function primarily of the credit spread. Output and inflation actually rise above their steady state values before jumping to those values once the zero lower bound stops binding. Relative to no intervention, the economy exits the zero lower bound only one period earlier. 
Figure 8: Deficit-financed purchases and tax rebates in rigid wage model
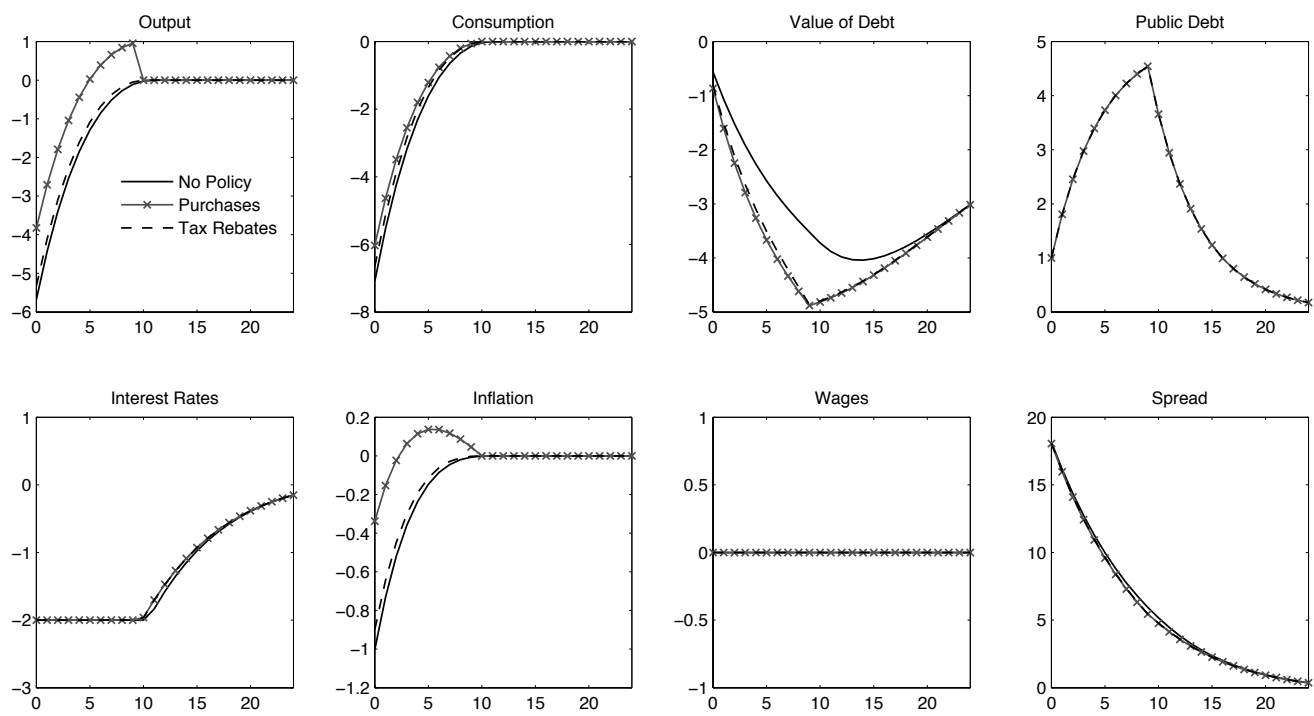

\subsection{Role of Credit Spreads}

The choice between purchases and transfers/tax rebates depends, in part, on which policy is more effective in reducing credit spreads. Since the solution for the model at the zero lower bound is nonlinear, the model response to various fiscal shocks will not be invariant to the size of the shock. In other words, a $2 \%$ of GDP deficit-financed increase in purchases is not simply a scaled version of the $1 \%$ of GDP experiment; therefore, a fiscal multiplier is not readily defined. Moreover, given that the model features endogenous state variables, the response of various variables of interest will depend on the persistence and shape of the fiscal response, even if the total size of the fiscal intervention is held constant. However, to provide insight into the role of credit spreads, I consider a simple metric for computing output multipliers:

$$
M_{t}=\frac{\sum_{t=0}^{24}\left(y_{t}^{\text {pol }}-y_{t}^{\text {nopol }}\right)}{\sum_{t=0}^{24} x_{t}}
$$

where $y_{t}^{p o l}$ is the response of output, in log-deviations, under a particular fiscal intervention, $y_{t}^{\text {nopol }}$ is the response of output under no intervention, and $x_{t}$ is the total expenditure on the policy. The multiplier is a equally weighted sum over 24 quarters (6 years) of the deviations of output from the path it would have taken absent any intervention, conditional on the same underlying shock.

Two natural variables of interest are output (which is also employment in this model) and 
aggregate consumption. To isolate the effect of variations in the debt and income elasticity of the credit spread, I consider fiscal interventions of the following form: a 1\% of GDP increase in government purchases financed by current taxes or a $1 \%$ transfer from saver to borrower households in all periods. The underlying shock is a 5 percentage point increase in the financial shock that decays deterministically at rate $\rho=0.9$, and fiscal interventions end once the zero lower bound stops binding. Since it delivers the most realistic impulse responses, only the model with perfect wage rigidity is considered.

Table 3 provides output and consumption multipliers and the time to exit for different values of the debt and income elasticity parameters in the credit spread. As Table 3 shows, the output multiplier on government purchases exceeds the output multiplier on transfers, though transfers may be more effective in boosting aggregate consumption than government purchases. The effectiveness of transfers relative to purchases rises with the debt-elasticity of the credit spread $\chi_{b}$, and the time to exit the zero lower bound falls with $\chi_{b} \cdot{ }^{16}$ As suggested by the analysis earlier, a higher debt elasticity operates through two channels to boost the transfer multiplier. Higher debt elasticities raise the marginal propensity to consumer for borrower households - these household spend more of an temporary income they receive. Secondly, a higher debt elasticity lowers future borrowing costs. This credit market effect, which is not present in environments with rule of thumb agents, ensures that transfers have persistent effects. Transfer allow a faster decrease in credit spreads relative government purchases thereby increasing borrower consumption and increasing the relative effectiveness of transfers.

An increase in the income-elasticity of the credit spread $\chi_{n}$ (shown on the right-hand side of Table 3) tends to magnify the effect of either type of fiscal intervention with output multipliers approaching the values estimated by the Congressional Budget Office. The time to exit the zero lower bound increases because the fall in output from the financial shock feeds back into the credit spread, amplifying its effect. The amplification of both the underlying shock and the effect of fiscal policy is consistent with the analytical results shown earlier. Despite the importance of the debt and income elasticity parameters for fiscal policy, a simple regression of credit spread measures on output and private sector borrowing is unlikely to accurately estimate these parameters since the

\footnotetext{
${ }^{16}$ Evidence from Edelberg (2003) suggest very low elasticities of risk premia on consumer loans with respect to debt and borrowing. Using data from the Survey on Consumer Finances, even for large differences in income and personal debt, spreads vary by less than two percentage points. A naive extrapolation suggests elasticity of spreads with respect to borrowing and income of less than 0.01 - an order of magnitude lower than shown in the numerical experiments in this section. However, given the extensive use of non-price tools such as credit limits, downpayments, and credit history in rationing credit, these elasticities should be viewed as a lower bound rather than an upper bound on credit spread elasticities.
} 
Table 3: Output and consumption multipliers

\begin{tabular}{lcccc|ccccc}
$\chi_{n}=0.0$ & $\chi_{b}=0.0$ & $\chi_{b}=0.1$ & $\chi_{b}=0.2$ & $\chi_{b}=0.3$ & $\chi_{n}=0.2$ & $\chi_{b}=0.0$ & $\chi_{b}=0.1$ & $\chi_{b}=0.2$ & $\chi_{b}=0.3$ \\
\hline \hline Purchases & $=1 \%$ & of GDP & & & & & & \\
\hline Exit & $16 \mathrm{qtr}$ & $15 \mathrm{qtr}$ & $14 \mathrm{qtr}$ & $13 \mathrm{qtr}$ & Exit & $17 \mathrm{qtr}$ & $16 \mathrm{qtr}$ & $15 \mathrm{qtr}$ & $14 \mathrm{qtr}$ \\
Output & 1.35 & 1.22 & 1.19 & 1.15 & Output & 2.53 & 2.37 & 2.12 & 1.92 \\
Consumption & 0.35 & 0.22 & 0.19 & 0.15 & Consumption & 1.53 & 1.37 & 1.12 & 0.92 \\
\hline Transfers & $=1 \%$ & of GDP & & & & & & \\
\hline Exit & $16 \mathrm{qtr}$ & $14 \mathrm{qtr}$ & $13 \mathrm{qtr}$ & $12 \mathrm{qtr}$ & Exit & $17 \mathrm{qtr}$ & $15 \mathrm{qtr}$ & $14 \mathrm{qtr}$ & $12 \mathrm{qtr}$ \\
Output & 0.00 & 0.26 & 0.29 & 0.30 & Output & 0.00 & 0.48 & 0.50 & 0.52 \\
Consumption & 0.00 & 0.26 & 0.29 & 0.30 & Consumption & 0.00 & 0.48 & 0.50 & 0.52
\end{tabular}

error term is likely to be highly correlated with output and borrowing.

\subsection{Savers and Borrowers Policy Preferences}

Given that the model features distinct agents, optimal fiscal and monetary policy will, in general, depend on the weighting of each agent in the social welfare function. Moreover, even in the absence of financial shocks, the fiscal authority may wish to redistribute income among agents by changes in the level of the public debt. ${ }^{17}$ However, even at the zero lower bound - where fiscal policy is most relevant - savers and borrowers may disagree on which fiscal interventions they prefer and may, in some cases, prefer no intervention at all. Furthermore, when fiscal policies are financed by deficits, preferences will differ on the rate with which the deficit is returned to its steady state. As shown earlier, when the credit spread is fairly debt inelastic, tax rebates and transfers simply have the effect of redistributing income and consumption with little effect on aggregates and savers may prefer inaction to any fiscal intervention. Importantly, the financial shock itself is redistributive saver households benefit from the increase in credit spreads because, under the assumption that intermediary profits flow to the savers and absent no default (no real costs of intermediation), intermediary profits increase with a rise in spreads.

A simple metric, analogous to the output multiplier, for gauging household's preferences over various policy options is the difference in household consumption under a fiscal intervention relative to no intervention:

$$
\frac{1}{24} \sum_{t=0}^{24}\left(c_{t}^{i, p o l}-c_{t}^{i, n o p o l}\right) i \epsilon\{s, b\}
$$

Table 4 displays each households' consumption relative to the no intervention baseline under two

\footnotetext{
${ }^{17}$ For instance, a higher government debt implies greater inequality in steady state given higher interest payments to borrowers. Aiyagari and McGrattan (1998) consider the optimal level of public debt in a model with idiosyncratic risk and incomplete markets.
} 
Table 4: Relative consumption (\% deviation)

\begin{tabular}{lccccc} 
Fiscal Parameter: & $\varphi_{b}=0.1$ & $\varphi_{b}=0.2$ & $\varphi_{b}=0.3$ & $\varphi_{b}=0.4$ & $\varphi_{b}=0.5$ \\
\hline \hline Purchases & $=1 \%$ & of GDP & & & \\
\hline Saver Household & -0.03 & 0.06 & 0.09 & 0.10 & 0.10 \\
Borrower Household & 1.01 & 0.81 & 0.78 & 0.71 & 0.65 \\
\hline Tax Rebates & $=1 \%$ & of GDP & & & \\
\hline Saver Household & -0.12 & -0.04 & -0.03 & -0.02 & -0.02 \\
Borrower Deviation & 0.72 & 0.52 & 0.41 & 0.33 & 0.28
\end{tabular}

alternative fiscal policies:

1. Debt-financed increase in government purchases by $1 \%$ of GDP for all periods the zero lower bound binds

2. Debt-financed tax rebates to all households of $1 \%$ of GDP for all periods the zero lower bound binds

Under the assumption of zero initial public debt, these policies imply equivalent fiscal cost for the government, with the debt increasing during the ZLB episode and subsequently converging back to zero. The rate at which taxes are raised to pay back the public debt is controlled by the parameter $\varphi_{b}$ with higher values leading to a faster increase in taxes. As Table 4 indicates, saver households prefer policies that minimize the increase in the public debt, and therefore minimize the degree of transfers. Borrower households instead prefer a greater degree of deficit-financing which increases disposable income in the near term when the cost of credit is high. In the particular calibration considered $\left(\chi_{b}=0.1, \chi_{n}=0\right)$, any fiscal intervention offers a higher consumption path for borrowers relative to no intervention. In contrast, savers often enjoy a higher consumption path absent any fiscal intervention. Under this calibration, savers never prefer tax rebates (even though savers receive this rebate and are paid market rate on public debt), and only prefer purchases if the transfer component is limited. Deficit-financed purchases are the policy that most frequently increases the consumption path of both households relative to the baseline of no intervention. The preference for government purchases in this example is somewhat driven by the low debt elasticity of the credit spread, which renders transfers less effective for stabilization. Though this analysis abstracts from welfare costs of labor supply and inflation, it illustrates the potential for disagreement over fiscal policy and deficits. 


\section{Conclusion}

Existing representative agent models, by Ricardian equivalence, rule out any role for transfers, tax rebates, or deficit-financing as tools for stabilizing business cycles. This paper analyzes a borrower-lender model with credit spreads to examine transfers as an instrument of fiscal policy and compare transfers to government purchases. I showed that deficit-financed policies such as an increase in purchases or temporary lump sum tax rebates financed budget deficits can be expressed as a combination of two fiscal instruments: purchases and transfers, and I distinguished between two important channels for these instruments: aggregate supply and aggregate demand. I find, in general, that government purchases are a more effective means of boosting output and employment than transfers/tax rebates, primarily because of its large wealth effects on labor supply.

The aggregate supply channel for fiscal policy is the wealth effect on labor supply. Purchases or transfers will boost output only to the extent that the policy increases labor supply. In the absence of wealth effects, the aggregate supply channel is inoperative and neither purchases nor transfers have any effect on output. In the presence of wealth effects, purchases increase output by making both agents poorer, but transfers (as implemented by tax rebates) have little effect on aggregate labor supply. On the whole, the aggregate supply channel favors purchases over transfers for boosting output and employment.

The aggregate demand channel for fiscal policy stems from countercyclical markups due to sticky prices. While both fiscal policy instruments can boost demand, monetary policy can undo or amplify any fiscal shock. When monetary policy is unconstrained, fiscal policy is redundant for aggregate demand management. While fiscal policy may play a role in the distribution of production or consumption, monetary policy is sufficient to manage the inflation-output tradeoff. However, when monetary policy is constrained, fiscal policy becomes the sole tool for managing aggregate demand. As a result, the choice between purchases and transfers or some combination thereof is not inconsequential. As the numerical experiments in Section 6 illustrate, both tools of fiscal policy can have substantial effects on aggregate demand at the zero lower bound, and the choice between these policies will depend on the details of the credit spread. However, the low estimated elasticities of credit spreads to borrowing and income as reported in Edelberg (2003) suggest that tax rebates and transfers are unlikely to match government purchases in boosting output, employment or consumption.

Given the role of the credit spread elasticities in determining the multiplier on transfers rel- 
ative to government spending, the details of financial intermediation are likely to be important for determining relative multipliers. While there is no single consensus model of financial intermediation, particularly among households, business cycle models of intermediation have generally focused on the importance of either collateral constraints for the borrower or the net worth of the intermediary. ${ }^{18}$ In a model where quantity is constrained by the value of collateral, fiscal multiplier depend on the effect of policy on the shadow price of the collateral constraint. Both transfers and government purchases by boosting disposable income could ease these constraints temporarily or may boost the value of collateral, with the multiplier depending on how much each policy boosts borrower's disposable income. Moreover, given the importance of housing as household collateral, relative multipliers are also likely to depend heavily on the effect of these policies on housing values. Even for relatively large fiscal outlays, these effects are likely to be small absent a policy directed towards housing.

Alternatively, in a model where the cost of financial intermediation depends on the net worth of intermediaries, fiscal multipliers are likely to operate via the default channel. If the net worth of financial intermediaries is low, the cost of credit will only fall if intermediaries are able to restore their net worth. Absent direct recapitalizations or changes in dividend policy, fiscal policy is only likely to impact intermediary net worth by reducing default rates. By raising disposable income either by raising output or through direct transfers, fiscal policy may reduce default rates and increase the rate at which intermediaries recapitalize. Alternatively, if fiscal policy leads to more defaults via households' decisions to strategically default, could increase the cost of credit resulting in negative multipliers. In the end, more direct fiscal instruments that address the cause of the rise in credit costs - whether declining house prices or insufficient intermediary net worth - are likely to be more effective than indirect policies such as transfers and government purchases.

Given multiple instruments of policy, a natural extension will be analysis of optimal fiscal policy at the zero lower bound and further analysis of disagreement among agents over policy. Endogenizing the credit spread will be another important extension given the dependence of policy on the behavior of the credit spread. These extensions are ongoing research.

\footnotetext{
${ }^{18}$ For the former, see Kiyotaki and Moore (1997) or Iacoviello (2005).For the latter, see Bernanke, Gertler and Gilchrist (1999).
} 


\section{References}

Agarwal, Sumit, Chunlin Liu, and Nicholas S. Souleles. 2007. "The reaction of consumer spending and debt to tax rebates - evidence from consumer credit data." Journal of Political Economy, 115(6): 986-1019.

Aiyagari, S. Rao, and Ellen R. McGrattan. 1998. "The optimum quantity of debt." Journal of Monetary Economics, 42(3): 447-469.

Bernanke, Ben S., Mark Gertler, and Simon Gilchrist. 1999. "The financial accelerator in a quantitative business cycle framework." Handbook of Macroeconomics, 1: 1341-1393.

Bilbiie, Florian, Tommaso Monacelli, and Roberto Perotti. 2012. "Public debt and redistribution with borrowing constraints."

Blanchard, Olivier, and Jordi Gali. 2010. "Labor markets and monetary policy: A New Keynesian model with unemployment." American Economic Journal: Macroeconomics, 2(2): 1-30.

Campbell, Jeremy R., and Zvi Hercowitz. 2005. "The role of collateralized household debt in macroeconomic stabilization."

Carroll, Christopher D. 2001. "A theory of the consumption function, with and without liquidity constraints." The Journal of Economic Perspectives, 15(3): 23-45.

Curdia, Vasco, and Michael Woodford. 2010. "Credit spreads and fiscal policy." Journal of Money, Credit and Banking, 42(6): 3-35.

Edelberg, Wendy. 2003. "Risk-based pricing of interest rates in household loan markets." $U n$ published manuscript.

Eggertsson, Gauti B., and Michael Woodford. 2003. "The zero bound on interest rates and optimal monetary policy." Brookings Papers on Economic Activity, , (1): 139-234.

Eggertsson, Gauti B, and Paul Krugman. 2012. "Debt, deleveraging, and the liquidity trap: A Fisher-Minsky-Koo approach." The Quarterly Journal of Economics, 127(3): 1469-1513.

Gali, Jordi, David Lopez-Salido, and Javier Valles. 2007. "Understanding the effects of government spending on consumption." Journal of the European Economic Association, 5(1): 227270. 
Giambattista, Eric, and Steven Pennings. 2012. "Government transfer multiplier."

Greenwood, Jeremy, Zvi Hercowitz, and Gregory W. Huffman. 1988. "Investment, capacity utilization, and the real business cycle." The American Economic Review, 78(3): 402-417.

Guerrieri, Veronica, and Guido Lorenzoni. 2011. "Credit crises, precautionary savings, and the liquidity trap." National Bureau of Economic Research.

Hansen, Gary D. 1985. "Indivisible labor and the business cycle." Journal of Monetary Economics, 16(3): 309-327.

Heathcote, Jonathan. 2005. "Fiscal policy with heterogeneous agents and incomplete markets." Review of Economic Studies, 72(1): 161-188.

Iacoviello, Matteo. 2005. "House prices, borrowing constraints, and monetary policy in the business cycle." American Economic Review, 739-764.

Johnson, David S., Jonathan A. Parker, and Nicholas S. Souleles. 2006. "Household expenditure and the income tax rebates of 2001." The American Economic Review, 96(5): 15891610.

Kaplan, Greg, and Gianluca Violante. 2011. "A model of the consumption response to fiscal stimulus payments." National Bureau of Economic Research.

Kiyotaki, Nobuhiro, and John Moore. 1997. "Credit cycles." Journal of Political Economy, $105(2)$.

Mankiw, N. Gregory. 2000. "The savers-spenders theory of fiscal policy." American Economic Review, 90(2): 120-125.

Monacelli, Tommaso. 2009. "New Keynesian models, durable goods, and collateral constraints." Journal of Monetary Economics, 56(2): 242-254.

Oh, Hyunseung, and Ricardo Reis. 2012. "Targeted transfers and the fiscal response to the Great Recession." Journal of Monetary Economics, 59(S): S50-S64.

Rogerson, Richard. 1988. "Indivisible labor, lotteries and equilibrium." Journal of Monetary Economics, 21(1): 3-16. 
Schmitt-Grohé, Stephanie, and Martın Uribe. 2003. "Closing small open economy models." Journal of International Economics, 61(1): 163-185.

Shimer, Robert. 2012. "Wage rigidities and jobless recoveries." Journal of Monetary Economics, 59(S): S65-S77.

Woodford, Michael. 2011. "Simple analytics of the government expenditure multiplier." American Economic Journal: Macroeconomics, 1-35.

\section{A Extensions}

In this section, I briefly consider fiscal policy in a model where a subset of the population operates as rule of thumb agents who simply consume current income each period and a model where agents face a borrowing constraint. This section relates to a literature on fiscal policy and rule of thumb agents developed by Mankiw (2000) and Gali, Lopez-Salido and Valles (2007), and a literature examining the effects of monetary policy when agents face borrowing constraints such as Iacoviello (2005) and Monacelli (2009). As this section illustrates, the credit spread model considered in this paper can easily be related to rule of thumb or borrowing constraint models and, therefore, the policy implications are likely to carry over to a broader class of DSGE models.

\section{A.1 Rule of Thumb Agents}

Rule of thumb agents face a static optimization problem and choose hours period-by-period facing a simple budget constraint with consumption equal to current disposable income:

$$
\begin{aligned}
U_{c}\left(C_{t}^{y}, N_{t}^{y}\right) W_{t} & =-U_{h}\left(C_{t}^{y}, N_{t}^{y}\right) \\
C_{t}^{y} & =W_{t} N_{t}^{y}-T_{t}
\end{aligned}
$$

Log-linearizing these equilibrium conditions and combining with the equilibrium conditions for the firms and saver households discussed earlier delivers a closed form solution for output in terms of 
government purchases and taxes:

$$
\begin{aligned}
y_{t}= & \frac{\alpha}{\left(\alpha+s_{c} \bar{\sigma}(1-\alpha)+s_{c} \frac{1-s_{y}}{1-l_{y}} \frac{\sigma_{s}}{\varphi_{s}}-s_{c}(1-\alpha) \phi v\right)} g_{t} \\
& -\frac{\alpha \phi \bar{Y} / \sigma_{y} \bar{c}_{y}}{\left(\alpha+s_{c} \bar{\sigma}(1-\alpha)+s_{c} \frac{1-s_{y}}{1-l_{y}} \frac{\sigma_{s}}{\varphi_{s}}-s_{c}(1-\alpha) \phi v\right)} t \\
\phi= & s_{y} \frac{\sigma_{y}}{\varphi_{y}}-\left(1-s_{y}\right) \frac{\sigma_{s}}{\varphi_{s}} \frac{l_{y}}{1-l_{y}} \\
v= & \left(1-\frac{\overline{w n}_{y}}{\sigma_{y} \bar{c}_{y}}\right) /\left(\frac{1}{\varphi_{b}}+\frac{\overline{w n}_{y}}{\sigma_{y} \bar{c}_{y}}\right)
\end{aligned}
$$

The multiplier on government spending has several terms similar to the multiplier derived in Section 5 , with the parameters $\phi$ and $v$ as the new terms. For Frisch elasticies less than unity, $v<1$, and for households with sufficient symmetry, $\phi \approx 0$. Therefore, a tax reduction for the borrower household has negligible effect on output for plausible calibrations, and the government spending multiplier remains below unity, consistent with the numerical experiments shown in Figure 1. Intuitively, a transfer from one household to the other has offsetting effects on the labor supply of each household, leaving total labor supply relatively unchanged and, therefore, output unchanged. To the extent that $\phi>0$, tax rebates will be expansionary and the government spending multiplier will be larger than in the representative agent benchmark.

Under sticky prices, analytical solutions with rule of thumb agents can be obtained under the assumption of GHH preferences or wage rigidity that eliminates a labor supply effect. For simplicity and comparability to the rest of the paper, I consider the case of rigid wages. The Phillips curve from Section 4.2 obtains along with an intertemporal IS curve of the form:

$$
\begin{aligned}
y_{t}-g_{t} & =E_{t}\left(y_{t+1}-g_{t+1}\right)-s_{c} \sigma_{s}\left(1-s_{y}\right)\left(i_{t}^{d}-E_{t} \pi_{t+1}\right)-s_{c} s_{y}\left(E_{t} c_{t+1}^{y}-c_{t}^{y}\right) \\
c_{t}^{y} & =\frac{\overline{w n}_{y}}{\bar{c}_{y}} \frac{1}{\alpha} y_{t}-\frac{\bar{Y}}{\bar{c}_{y}} \operatorname{tax}_{t} \\
\pi_{t} & =\frac{\kappa}{\alpha}(1-\alpha) y_{t}+\beta E_{t} \pi_{t+1}
\end{aligned}
$$

The last term in the IS equation can be treated as equivalent to the credit spread $\omega_{t}$, and responds to both changes in income and transfers. A temporary increase in transfers that is gradually withdrawn, as in the case of a debt-financed tax rebate, is equivalent to a fall in the credit spread that eventually becomes positive as the transfer turns negative when taxes are raised to return the public debt to its steady state. Relative to the credit spread model, transfers appear directly in the 
intertemporal IS equation instead of operating indirectly through private sector debt. As before, when monetary policy is unconstrained, the Phillips curve is unchanged and monetary policy is free to target any combination of inflation and output subject to the Phillips curve tradeoff.

When monetary policy is constrained by the zero lower bound, both purchases and transfers may be used for stabilization and an explicit tax rebate multiplier can be derived when there is a constant probability that the shock causing the zero lower bound to bind disappears. While a financial shock no longer appears because of the absence of intermediation, any of the shocks that cause the zero lower bound to bind in representative agent models - like a discount rate shock would suffice here. ${ }^{19}$ The solution for output at the zero lower bound is similar to the solution derived in Section 6 with the addition of a multiplier on the tax rebate:

$$
\begin{aligned}
y_{z l b} & =\nu_{g}^{*}\left(g_{z l b}-\operatorname{tax}_{z l b}\right)-\zeta \\
\nu_{g}^{*} & =\frac{(1-\rho)(1-\beta \rho)}{(1-\rho)(1-\beta \rho)\left(1-i n c_{y} \frac{1}{\alpha}\right)-s_{c}\left(1-s_{b}\right) \sigma_{s} \frac{\kappa}{\alpha}(1-\alpha) \rho}
\end{aligned}
$$

where $i n c_{y}$ is the rule-of-thumb agents share of wage income in national income. Comparison to the multiplier derived in section 6 reveals that the multiplier $\nu_{g}$ may be higher or lower; the effect of higher inflation reducing real interest rates (the last term in the denominator) is attenuated relative to the saver/borrower model while the presence of rule-of-thumb agents raises the direct effect of government spending on the consumption of rule-of-thumb agents (the $i n c_{y}$ term) and the multiplier. Unlike an old-style Keynesian model, the government spending multiplier and tax rebate multiplier are the same, and the balanced budget multiplier is zero.

The reason the multiplier is the same for both government spending and tax rebates is that both affect the savers consumption in the same way. A rise in government spending or equivalent fall in tax rebates raises aggregate demand by the same amount, and equilibrium in the goods market requires either a rise in output or a fall in the savers consumption induced by a rise in the real interest rate. With the nominal rate held constant and no direct effect of either policy on the Phillips curve, the savers consumption response is the same and, therefore, the output multiplier is the same for each policy. When the government's budget is balanced, the aggregate demand effects

\footnotetext{
${ }^{19}$ We can easily reintroduce the financial shock and credit spread by simply adding a measure of rule-of-thumb consumers to the existing saver/borrower model. Goods market clearing then implies that $Y_{t}=\eta_{s} C_{t}^{s}+\eta_{b} C_{t}^{b}+$ $\left(1-\eta_{s}-\eta_{b}\right) C_{t}^{y}$. As before, under the assumption of zero debt elasticity of the credit spread, the log-linearized economy at the zero lower bound is summarized by an aggregate intertemporal IS curve and the standard Phillips curve. Moreover, in a lifecycle model with distinct borrowing and credit spreads, the stochastic steady state would be characterized by saver households, borrower households, and households living in autarky.
} 
cancel out and the savers consumption decision is unchanged.

Finally, it's worth relating this equilibrium analysis of the zero lower bound with rule-of-thumb agents to the extensive literature on the determinants of consumption and the aggregate consumption function where the real interest rate is taken as fixed and exogenous. 20 The multipliers attached to any particular fiscal policy are heavily dependent on the behavior of the real interest rate, and therefore conclusions regarding fiscal multipliers are inherently general equilibrium questions. In the same way that the credit spread - absent wealth effects - does not alter the Phillips curve, a more complex (and realistic) theory of consumption is unlikely to alter the effects of fiscal policy away from the zero lower bound. Unless fiscal stabilization has large effects on the production side of the economy - that is, incentives to supply labor and capital - monetary policy can achieve the same aggregate demand objectives of fiscal policy away from the zero lower bound. The nature of the aggregate consumption function will only become relevant at the zero lower bound where fiscal policies that have larger affect on desired consumption will be preferred to policies with a smaller effect.

\section{A.2 Borrowing Constrained Agents}

A broad range of models consider a class of agents that are constrained either by an exogenous or endogenous borrowing constraint but assume a single rate for lending and borrowing funds. These model often assume that the borrowing constraint binds at all times and solve for the dynamics of the model by log-linearizing around a binding constraint. Relative to the rule of thumb model in the previous section and assuming an exogenous borrowing constraint, the equilibrium conditions become:

$$
\begin{aligned}
U_{c}\left(C_{t}^{b}, N_{t}^{b}\right) W_{t} & =-U_{h}\left(C_{t}^{b}, N_{t}^{b}\right) \\
C_{t}^{b}+\frac{1+i_{t-1}^{d}}{\Pi_{t}} B_{t-1} & =W_{t} N_{t}^{b}+B_{t} \\
B_{t} & \geq \bar{B}
\end{aligned}
$$

To a log-linear approximation, the borrower's budget constraint differs from the rule-of-thumb budget constraint only by including the lagged interest rate. If steady state interest payments are small, this term can be safely disregarded and the fiscal multipliers obtained in Section 7.1 remain a good approximation in the case of exogenous constraints. Without further assumptions on the

\footnotetext{
${ }^{20}$ See for example Carroll (2001) and Kaplan and Violante (2011).
} 
model, a general characterization of fiscal multipliers with an endogenous borrowing constraint is difficult.

Under sticky prices and a demand driven labor market, a similar Phillips curve and intertemporal IS curve determine output and inflation. When borrowers are constrained by an endogenous or exogenous constraint, their optimal choice of borrowing is governed by an Euler equation with nonzero Lagrange multiplier on the binding contraint:

$$
\lambda_{t}^{b}=\gamma E_{t} \lambda_{t+1}^{b} \frac{1+i_{t}^{d}}{\Pi_{t+1}}+\Theta_{t}
$$

where the Lagrange multiplier represents the shadow price of the constraint. Since the constraint is assumed to be always binding for sufficiently small shocks, the borrower's Euler equation can be log-linearized and summed with the saver's Euler equation to obtain an intertemporal IS curve of the form:

$$
y_{t}-g_{t}=E_{t}\left(y_{t+1}-g_{t+1}\right)-s_{c} \bar{\sigma}\left(i_{t}^{d}-E_{t} \pi_{t+1}\right)-s_{c} s_{b} \sigma_{b} \bar{\theta} \theta_{t}
$$

As before, the last term can be regarded as the credit spread, and changes in fiscal policy will shift the credit spread depending on the nature of the borrowing constraint. Importantly, the multiplier is likely to be changed by policy given that any change in income, wages, or taxes will affect the shadow price of the borrowing constraint. Though the mapping of a borrowing constraint model into the credit spread model will depend on further assumptions, the insights on fiscal policy from the credit spreads model should carry over to alternative models of borrowing and lending.

\section{A.3 Housing and Credit Spreads}

I maintain the assumption of patient and impatient households, but I now assume a single market interest rate for savers and households. Instead of a credit spread, impatient household are constrained to borrow only a possibly time-varying fraction of the value of their residence. The impatient household's chooses :

$$
\begin{aligned}
\max _{\left\{C_{t}^{b}, N_{t}^{b}, B_{t}, H_{t}^{b}\right\}} & E \sum_{t=0}^{\infty} \beta^{t} U\left(C_{t}^{b}, N_{t}^{b}, H_{t}^{b}\right) \\
\text { subject to } C_{t}^{b} & =W_{t} N_{t}^{b}-\frac{1+i_{t-1}^{d}}{\Pi_{t}} B_{t-1}+B_{t}-T_{t}+Q_{t}\left(H_{t-1}^{b}-H_{t}^{b}\right) \\
B_{t} & \leq \chi_{t} Q_{t} H_{t}^{b}
\end{aligned}
$$


Relative to the equilibrium conditions in Section 3, the Euler equation changes and a housing Euler equation is introduced:

$$
\begin{aligned}
\lambda_{t}^{b} & =\gamma E_{t} \lambda_{t+1}^{b}\left(\frac{1+i_{t}^{d}}{\Pi_{t}}+\Theta_{t}\right) \\
\lambda_{t}^{b} Q_{t} & =\gamma E_{t} \lambda_{t+1}^{b}\left(r_{h, t+1}^{b}+Q_{t+1}\right)+\Theta_{t} \chi_{t} Q_{t}
\end{aligned}
$$

Furthermore, if impatient households are the only agents that demand housing services and the supply of housing is fixed, the housing Euler equation will determine the market-clearing price of housing. We can log-linearize the model around a steady state assuming that the collateral constraint is always binding. Under these assumptions, an aggregate IS equation of the same form as the rule-of-thumb case emerges. To a log-linear approximation:

$$
\begin{aligned}
y_{t}-g_{t} & =E_{t}\left(y_{t+1}-g_{t+1}\right)-s_{c} \sigma_{s}\left(1-s_{b}\right)\left(i_{t}^{d}-E_{t} \pi_{t+1}\right)-s_{c} s_{b}\left(E_{t} c_{t+1}^{b}-c_{t}^{b}\right) \\
c_{t}^{b} & =\frac{\overline{w n}_{b}}{\bar{c}_{b}} \frac{1}{\alpha} y_{t}-\frac{\bar{Y}}{\bar{c}_{b}} \operatorname{tax}_{t}+\frac{\bar{B}}{\bar{c}_{b}}\left(\chi_{t}+q_{t}\right)-\frac{(1+\bar{r}) \bar{B}}{\bar{c}_{b}}\left(\chi_{t-1}+q_{t-1}\right) \\
\pi_{t} & =\frac{\kappa}{\alpha}(1-\alpha) y_{t}+\beta E_{t} \pi_{t+1}
\end{aligned}
$$

The preceding equations along with a monetary policy rule do not fully specify the equilibrium of the economy; the borrower household's Euler equation and housing Euler equation are needed to determine the dynamics of housing prices and the Lagrange multiplier on the borrowing constraint.

The growth rate of borrower's consumption takes the place of the credit spread in the aggregate IS equation just as in the case of rule-of-thumb households:

$$
\begin{aligned}
E_{t}\left(c_{t+1}^{b}-c_{t}^{b}\right)= & \gamma_{y} E_{t}\left(y_{t+1}-y_{t}\right)-\gamma_{t a x} E_{t}\left(\operatorname{tax}_{t+1}-\operatorname{tax}_{t}\right) \\
& +\gamma_{b}\left(E_{t} \chi_{t+1}-(2+\bar{r}) \chi_{t}+(1+\bar{r}) \chi_{t-1}\right) \\
& +\gamma_{b}\left(E_{t} q_{t+1}-(2+\bar{r}) q_{t}+(1+\bar{r}) q_{t-1}\right)
\end{aligned}
$$

where $\gamma_{y}, \gamma_{t a x}$, and $\gamma_{b}$ are the appropriate constants. An exogenous tightening of the collateral constraint can be represented as a fall in $\chi_{t}$ and, ignoring the equilibrium dynamics of housing prices, will act like an increase in the credit spread so long as the stochastic process for $\chi_{t}$ is dominated by the middle term for some period of time. In particular, an $\operatorname{AR}(3)$ process of $\chi_{t}$ could generate an $\mathrm{AR}(1)$ process for the "interest-rate" shock represented by borrower consumption growth in the aggregate IS equation. 
The inclusion of housing dynamics further complicates matters since simply a fall in housing prices does not guarantee at rise in borrower consumption growth beyond the initial period. Nevertheless, it appears plausible that a collateral shock could cause act in the same manner as a credit spread shock in the aggregate IS equation even with endogenous house prices. Stronger conclusions require greater structure placed on the saver household's demand for housing and residential investment which will both determine the market clearing housing price.

\section{B Equivalence with Overlapping Generations Model}

In this section, I show that the steady state of the model with infinitely-lived agents with differing degrees of time preference is isomorphic to the steady state of a model with finitely lived agents who share the same rate of time preference but differ in effective labor over the life cycle.

Household live $T$ periods with variation in the disutility of labor supply over the life cycle, and each generation that dies in a period is replaced by a generation of equal measure in the next period so that the total population is constant. Household choose consumption, hours worked, and whether to borrow or save in each period. Formally, for each generation $i \epsilon\{0,1, \ldots T\}$, household's optimization problem is:

$$
\begin{aligned}
\max & E_{0} \sum_{t=0}^{T-i} \beta^{t}\left\{u\left(C_{t}(i)\right)-\theta_{i}\right\} \\
C_{t}(i)= & W_{t} N_{t}(i)+B_{t}(i)-\frac{1+i_{t-1}^{b}}{\Pi_{t}} B_{t-1}(i)-D_{t}(i)+\frac{1+i_{t-1}^{d}}{\Pi_{t}} D_{t-1}(i)+\Pi_{t}^{f}-T_{t} \\
D_{t}(i) \geq & 0 \\
B_{t}(i) \geq & 0 \\
B_{T-i}(i) & =0
\end{aligned}
$$

where $\theta_{i}$ is an exogenous process for effective labor supply that captures the hump-shaped profile of earnings over the lifecycle. The household is prohibited from borrowing in the final period of life. The first-order conditions characterizing the household's optimal consumption and savings 
decisions are given below:

$$
\begin{aligned}
u_{c}\left(C_{t}(i), N_{t}(i)\right) & =\lambda_{t}(i) \\
-u_{n}\left(C_{t}(i), N_{t}(i)\right) & =\lambda_{t}(i) W_{t} \theta_{i} \\
\lambda_{t}(i) & =\beta E_{t} \lambda_{t+1}(i) \frac{\left(1+i_{t}^{d}\right)\left(1+\omega_{t}\right)}{\Pi_{t+1}}-\phi_{t}^{b}(i) \\
\lambda_{t}(i) & =\beta E_{t} \lambda_{t+1}(i) \frac{1+i_{t}^{d}}{\Pi_{t+1}}+\phi_{t}^{d}(i) \\
\lambda_{T-i}(i) & =-\phi_{T-i}^{b}(i) \\
\lambda_{T-i}(i) & =\phi_{T-i}^{d}(i) \\
\phi_{t}^{b}(i) B_{t}(i) & =0 \\
\phi_{t}^{d}(i) D_{t}(i) & =0
\end{aligned}
$$

Household optimality requires that households do not borrow or save in the final period. Subtracting the Euler equation for borrowing from the Euler equation for deposits shows that households never simultaneously borrow and save, but may find it optimal to live in autarky:

$$
0=\beta E_{t} \frac{\lambda_{t+1}(i)}{\Pi_{t+1}} \omega_{t}-\left(\phi_{t}^{d}+\phi_{t}^{b}\right)
$$

I consider a steady allocation of consumption, borrowing and labor supply across generations where wages, interest rates, and the price level are constant, and assume that the utility functions and distribution of $\theta_{i}$ over the generations are sufficient to guarantee that a steady state exists.

The firm's problem, the intermediaries problem, fiscal policy, and monetary policy are unchanged from the discussion in Section 3. Market clearing requires:

$$
\begin{aligned}
Y_{t} & =\sum_{i=0}^{T} C_{t}(i)+G_{t} \\
N_{t} & =\sum_{i=0}^{T} N_{t}(i)
\end{aligned}
$$

A steady state of the overlapping generations model with credit frictions is a set of aggregate quantities $\left\{\bar{Y}, \bar{N}, \bar{C}, \bar{F}, \bar{K}, \bar{\Pi}_{f}\right\}$, a distribution of consumption, labor supply, deposits and borrowings over generations $\left\{\bar{C}_{i}, \bar{N}_{i}, \bar{D}_{i}, \bar{B}_{i}, \bar{\lambda}_{i}, \bar{\phi}_{i}^{d}, \bar{\phi}_{i}^{b}\right\}_{i=0}^{T}$, a set of prices $\{\bar{W}, \bar{\Pi}, \bar{i} d, \bar{\omega}, \overline{M C}\}$, a fiscal policy $\left\{\bar{B}_{g}, \bar{T}, \bar{G}, \overline{r e b}\right\}$ that jointly satisfy the steady state versions of: 
1. Household optimality conditions (A.3) - (A.10)

2. Household budget constraints

3. Firm optimality conditions in (15)

4. Government budget constraint, fiscal rule, and solvency condition (10)

5. Monetary policy rule (13)

6. Market-clearing conditions

Given a definition for the steady state of the overlapping generations model, for suitable choices of the distribution of $\theta_{i}$ and other model parameters, the steady state of the infinite horizon model is equivalent to the steady state of the overlapping generations model.

Proposition 4. Consider a steady state of the overlapping generations model. There exists a set of discount rates and functions for household utility that give the provide steady state in the infinite horizon model.

Proof. Since the firm's problem, intermediaries' problem, fiscal and monetary policy are unchanged in the overlapping generation model, a steady state in the OLG model satisfies parts 3-5 of the steady state version of the definition of an equilibrium in the infinite horizon model. It remains to show that household optimality conditions and market clearing conditions may be satisfied.

Let $\Omega$ is the set of borrowers in $i \epsilon\{0,1, \ldots T\}$. Savers and borrowers consumption and labor supply can be defined in the OLG model and will satisfy the corresponding market clearing conditions (12) - (13) in the infinite horizon model:

$$
\begin{aligned}
\bar{C}_{s} & =\frac{1}{1-\pi_{b}} \sum_{i \epsilon \Omega^{c}} \bar{C}_{i} \\
\bar{C}_{b} & =\frac{1}{\pi_{b}} \sum_{i \in \Omega} \bar{C}_{i} \\
\bar{N}_{s} & =\frac{1}{1-\pi_{b}} \sum_{i \epsilon \Omega^{c}} \bar{N}_{i} \\
\bar{N}_{b} & =\frac{1}{\pi_{b}} \sum_{i \in \Omega} \bar{N}_{i}
\end{aligned}
$$

For suitable definitions of the utility functions for each household, household's labor supply condi- 
tions hold in steady state:

$$
\begin{aligned}
& U_{c}^{s}\left(\bar{C}_{s}, \bar{N}_{s}\right) \bar{W}=-U_{h}^{s}\left(\bar{C}_{s}, \bar{N}_{s}\right) \\
& U_{c}^{b}\left(\bar{C}_{b}, \bar{N}_{b}\right) \bar{W}=-U_{h}^{b}\left(\bar{C}_{b}, \bar{N}_{b}\right)
\end{aligned}
$$

Under the assumption that firm profits are only paid to savers and the assumption that $\theta_{i}$ implies only one switch from borrowing to saving midway through the lifecycle, summing the budget constraints of borrower household:

$$
\begin{aligned}
\sum_{i \in \Omega^{c}} \bar{C}_{i} & =\bar{W} \sum_{i \in \Omega^{c}} \bar{N}_{i}+\sum_{i \in \Omega^{c}} \bar{B}_{i}\left(1-\frac{1+\bar{i}_{b}}{\bar{\Pi}}\right)-\bar{T} \sum_{i \in \Omega^{c}} 1\left[i \epsilon \Omega^{c}\right] \\
\Rightarrow \bar{B} & =\frac{1}{\pi_{b}} \sum_{i \in \Omega^{c}} \bar{B}_{i}
\end{aligned}
$$

Finally, the interest rate and borrowing rate from the OLG model determine the discount rates in the infinite horizon model:

$$
\begin{aligned}
\beta & =\frac{1}{1+\bar{i}_{d}} \\
\gamma & =\frac{1}{\left(1+\bar{i}_{d}\right)(1+\bar{\omega})}
\end{aligned}
$$

\section{Equilibrium Conditions}

Household equilibrium conditions and relevant transversality conditions for $i \epsilon\{s, b\}$ :

$$
\begin{aligned}
\lambda_{t}^{i} & =u_{c}\left(C_{t}^{i}, N_{t}^{i}\right) \\
\lambda_{t}^{i} W_{t} & =-u_{n}\left(C_{t}^{i}, N_{t}^{i}\right) \\
\lambda_{t}^{s} & =\beta E_{t} \lambda_{t+1}^{s} \frac{1+i_{t}^{d}}{\Pi_{t+1}} \\
\lambda_{t}^{b} & =\gamma E_{t} \lambda_{t+1}^{b} \frac{\left(1+i_{t}^{d}\right)\left(1+\omega_{t}\right)}{\Pi_{t+1}}
\end{aligned}
$$


Law of motion for public sector and private sector debt:

$$
\begin{aligned}
B_{t} & =C_{t}^{b}-W_{t} N_{t}^{b}+\frac{1+i_{t-1}^{b}}{\Pi_{t}} B_{t-1}+T_{t} \\
B_{t}^{g} & =G_{t}+\frac{1+i_{t-1}^{d}}{\Pi_{t}} B_{t-1}^{g}-T_{t}
\end{aligned}
$$

Firm production, cost minimization, price setting and price level determination:

$$
\begin{aligned}
Y_{t} & =N_{t}^{\alpha} \\
W_{t} & =\alpha \frac{Y_{t}}{N_{t}} M C_{t} \\
1 & =\theta \Pi_{t}^{\nu-1}+(1-\theta)\left(\frac{K_{t}}{F_{t}}\right)^{\nu-1} \\
F_{t} & =\frac{\nu}{\nu-1} \lambda_{t}^{s} M C_{t} Y_{t}+\theta \beta E_{t} \Pi_{t+1}^{\nu} F_{t+1} \\
K_{t} & =\lambda_{t}^{s} Y_{t}+\theta \beta E_{t} \Pi_{t+1}^{\nu-1} K_{t+1}
\end{aligned}
$$

Monetary and fiscal policy rules and solvency condition:

$$
\begin{aligned}
\left(\frac{i_{t}^{d}}{\bar{r}_{d}}\right) & =\left(\Pi_{t}\right)^{\phi_{\pi}}\left(\frac{Y_{t}}{Y_{t}^{n}}\right)^{\phi_{y}} \\
T_{t} & =\phi_{b}\left(B_{t-1}^{g}-\bar{B}_{g}\right)-r e b_{t} \\
0 & =\lim _{T \rightarrow \infty} E_{t} \frac{P_{t}}{P_{T}} \frac{B_{T}^{g}}{\prod_{t}^{T}\left(1+i_{t-1}^{d}\right)}
\end{aligned}
$$

Credit spread determination:

$$
1+\omega_{t}=E_{t} \Gamma\left(B_{t}, W_{t+1} N_{t+1}^{b}, Z_{t}\right)
$$

Market-clearing conditions:

$$
\begin{aligned}
Y_{t} & =\eta C_{t}^{b}+(1-\eta) C_{t}^{s}+G_{t} \\
N_{t} & =\eta N_{t}^{b}+(1-\eta) N_{t}^{s}
\end{aligned}
$$

Exogenous processes:

$$
\begin{aligned}
\log \left(\frac{G_{t}}{\bar{G}}\right) & =\rho_{g}\left(\frac{G_{t-1}}{\bar{G}}\right)+\epsilon_{t}^{g} \\
r e b_{t}-\overline{r e b} & =\rho_{r e b}\left(r e b_{t-1}-\overline{r e b}\right)+\epsilon_{t}^{r e b}
\end{aligned}
$$




\section{Analytical Solutions}

As noted in Section 4, we presented solutions for the borrower-lender model if wages are rigid, $\chi_{n}=0$, and prices are flexible or monetary policy keeps inflation stable at all times. Here, we show how the model can be simplified and solved analytically under these conditions via the method of undetermined coefficients.

Consumption of borrower and lender households are determined in equilbrium by the Euler equations determining optimal saving behavior for each type of household. Along with these expressions, the budget constraint of the borrower household, the credit spread equation, and the resource constraint are also needed to solve for the tax multiplier.

$$
\begin{aligned}
c_{t}^{b} & =E_{t} c_{t+1}^{b}-\sigma_{b}\left(i_{t}+\omega_{t}-E_{t} \pi_{t+1}\right) \\
c_{t}^{s} & =E_{t} c_{t+1}^{s}-\sigma_{s}\left(i_{t}-E_{t} \pi_{t+1}\right) \\
y_{t} & =s_{c}\left(s_{b} c_{t}^{y}+\left(1-s_{b}\right) c_{t}^{s}\right)+g_{t} \\
\omega_{t} & =\chi_{b} b_{t} \\
c_{t}^{b} & =\frac{\bar{w} \bar{n}_{b}}{\bar{c}_{b}}\left(w_{t}+y_{t}\right)+\frac{\bar{b}}{\bar{c}_{b}} b_{t}-\frac{1+\bar{i}}{\bar{\pi}} \frac{\bar{b}}{\bar{c}_{b}}\left(b_{t-1}+i_{t-1}+\omega_{t-1}-\pi_{t}\right)-\frac{\bar{y}}{\bar{c}_{b}} t_{t} x_{t}
\end{aligned}
$$

Rigid real wages and flexible prices/inflation stabilization ensure that $y_{t}=w_{t}=\pi_{t}=0$. Combining the savers and borrowers Euler equations along with the aggregate resource constraint, the following expression for the nominal rate results:

$$
i_{t}=-\frac{s_{b} \sigma_{b}}{\tilde{\sigma}} \omega_{t}
$$

where $\tilde{\sigma}=s_{b} \sigma_{b}+\left(1-s_{b}\right) \sigma_{s}$ is the average intertemporal elasticity of substitution.

We can define a new variable $a_{t}=b_{t}+i_{t}+\omega_{t}$. Using (42) and (40), we obtain the following expression relating $a_{t}$ to $b_{t}$ :

$$
a_{t}=\left(1-\chi_{b}\left(1+\frac{s_{b} \sigma_{b}}{\tilde{\sigma}}\right)\right) b_{t}
$$

Using the expression for the nominal rate obtained above, we can reduce this system to a system 
of equation in $c_{t}^{b}$ and $a_{t}$ :

$$
\begin{aligned}
c_{t}^{b} & =\frac{\bar{b}}{\bar{c}_{b}} \frac{1}{1+\chi_{b}\left(1-\frac{s_{b} \sigma_{b}}{\tilde{\sigma}}\right)} a_{t}-\frac{1+\bar{i}}{\bar{\pi}} \frac{\bar{b}}{\bar{c}_{b}} a_{t-1}-\frac{\bar{y}}{\bar{c}_{b}} t_{t} x_{t} \\
c_{t}^{b} & =E_{t} c_{t+1}^{b}-\sigma_{b} \frac{\left(1-\frac{s_{b} \sigma_{b}}{\tilde{\sigma}}\right) \chi_{b}}{1+\chi_{b}\left(1-\frac{s_{b} \sigma_{b}}{\tilde{\sigma}}\right)} a_{t}
\end{aligned}
$$

A solution to this system of equation takes the following form, and we can compute the unknown coefficients using the method of undetermined coefficients:

$$
\begin{aligned}
& a_{t}=\alpha_{b} a_{t-1}+\alpha_{\tau} \operatorname{tax}_{t} \\
& c_{t}^{b}=\beta_{b} a_{t-1}+\beta_{\tau} \operatorname{tax}_{t}
\end{aligned}
$$

If $\chi_{b}=0$, then the credit spread is invariant to the level of debt and private sector debt follows a random walk. The coefficients are given below:

$$
\begin{aligned}
\beta_{b} & =-\bar{i} \frac{\bar{b}}{\bar{c}_{b}} \\
\beta_{\tau} & =-\frac{\bar{y}}{\bar{c}_{b}} \frac{\bar{i}}{1-\rho+\bar{i}} \\
\alpha_{b} & =1 \\
\alpha_{\tau} & =\frac{\bar{y}}{\bar{b}} \frac{1-\rho}{1-\rho+\bar{i}}
\end{aligned}
$$

We can also compute the solution in the case $\lim _{\chi_{b} \rightarrow \infty}$. As can be seen, the response of borrower consumption to the tax rebate is the same as in the case of a rule of thumb household. The remaining coefficients are given below:

$$
\begin{aligned}
\beta_{b} & =-(1+\bar{i}) \frac{\bar{b}}{\bar{c}_{b}} \\
\beta_{\tau} & =-\frac{\bar{y}}{\bar{c}_{b}} \\
\alpha_{b} & =\frac{1+\bar{i}}{1+\bar{i}+\sigma_{b} \frac{\bar{c}_{b}}{\bar{b}}} \\
\alpha_{\tau} & =\frac{(1-\rho) \frac{\bar{y}}{\bar{c}_{b}}}{(1+\bar{i}) \frac{\bar{b}}{\bar{c}_{b}}+\sigma_{b}}
\end{aligned}
$$

At the zero lower bound, output is no longer fixed at zero. Instead, the nominal interest rate does not respond to changes in fiscal policy. With the additional assumption of a labor share equal 
to one $(\alpha=1)$, we can express the system of equations determining output and consumption as follows:

$$
\begin{aligned}
y_{t}-g_{t} & =E_{t}\left(y_{t+1}-g_{t+1}\right)-s_{c} s_{b} \sigma_{b} \frac{\chi_{b}}{1+\chi_{b}} a_{t} \\
c_{t}^{b} & =E_{t} c_{t+1}^{b}-\sigma_{b} \frac{\chi_{b}}{1+\chi_{b}} a_{t} \\
c_{t}^{b} & =\frac{\bar{w} \bar{n}_{b}}{\bar{c}_{b}} y_{t}+\frac{\bar{b}}{\bar{c}_{b}} \frac{1}{1+\chi_{b}} a_{t}-(1+\bar{i}) \frac{\bar{b}}{\bar{c}_{b}} a_{t-1}-\frac{\bar{y}}{\bar{c}_{b}} t a x_{t}
\end{aligned}
$$

where $a_{t}=b_{t}+\omega_{t}$ and $i_{t}^{d}=0$. If $\chi_{b}=0$, then equation (56) determines output while the zero lower bound is binding. Output in this equation is a function only of government spending and, therefore, tax rebates have no effect on output.

In the case when $\chi_{b \rightarrow \infty}$, the coefficient on $a_{t}$ in equation (58) is zero and consumption by the borrower household is determined by current income and the tax rebate. We can solve for $a_{t}$ and find an expression for $y_{t}$. Since this expression contains the endogenous state variable $a_{t-1}$, an explicit analytical expression cannot be found.

$$
\begin{aligned}
\left(\sigma_{b}(1-\eta)+(1+\bar{i}) \frac{\bar{b}}{\bar{y}}\right) a_{t} & =-g_{t}+E_{t} g_{t+1}+\operatorname{tax}_{t}-E_{t} \operatorname{tax} x_{t+1}+(1+\bar{i}) \frac{\bar{b}}{\bar{y}} a_{t-1} \\
y_{t}-g_{t} & =E_{t}\left(y_{t+1}-g_{t+1}\right)-s_{c} s_{b} \sigma_{b} a_{t}
\end{aligned}
$$

